\title{
EL CONTROL CONSTITUCIONAL EN EL PERÚ: ¿UN MODELO AÚN POR ARMAR?
}

\section{CONSTITUTIONAL CONTROL IN PERU: A MODEL STILL TO ARM?}

\author{
Luciano López Flores ${ }^{1 *}$ \\ Abogado \\ Universidad de San Martín de Porres \\ llopezf@usmp.pe \\ Perú
}

\section{SUMARIO}

- Presentación

- El control constitucional jurisdiccional en perspectiva comparada

- Un breve repaso histórico para comprender las idas y vueltas del control constitucional en el Perú

- ¿Control constitucional de actos?

- ¿Quiénes tienen legitimidad para ejercer el control constitucional?

- Los espacios de acción del control difuso

- El funcionamiento del control concentrado y el rol del Tribunal Constitucional

- Algunas reflexiones a modo de conclusión

\section{RESUMEN}

Este trabajo versa sobre el modelo de control constitucional en el Perú. El autor acude a fuentes históricas, conceptuales $\mathrm{y}$ jurisprudenciales para, por un lado, identificar y comprender el contexto que da lugar a su origen $\mathrm{y}$, por otro, analizar su operatividad procesal en el Perú, desnudando las deficiencias que aquel presenta. De allí que se afirme que el control constitucional peruano es un «modelo aún por armar». Finalmente, plantea que la exploración del control de constitucionalidad sirve para precisar algunos conceptos que lo vinculan con la interpretación constitucional de manera muy estrecha, a la luz no solo de lo que sostiene la doctrina comparada actual, sino también de su recepción en la jurisprudencia del Tribunal Constitucional peruano.

\begin{abstract}
This paper deals with the model of constitutional control in Peru. The author comes to historical, conceptual and jurisprudential sources for, on the one hand, identify and understand the context that gives rise to its origin and secondly, to analyze its procedural operation in Peru, baring the deficiencies that presents. Hence it is claimed that the Peruvian judicial review is a "model even put together". Finally, it states that the exploration of judicial review serves to clarify some concepts that link it very closely with constitutional interpretation, in the light not only of what holds the current comparison doctrine but also its reception in the jurisprudence of the Peruvian Constitutional Court.
\end{abstract}

\section{PALABRAS CLAVE}

Control de constitucionalidad, Jurisdicción constitucional, Control difuso de constitucionalidad, Control concentrado de constitucionalidad, Tribunal Constitucional

\section{KEY WORDS}

Control of Constitutionality, Constitutional Jurisdiction, Judicial Review, Concentrated Control of Constitutionality, Constitutional Court

1 "Magister en Derecho con mención en Política Jurisdiccional y candidato a Doctor en Derecho por la Pontificia Universidad Católica del Perú (PUCP). Especialista en Derecho Constitucional, Procesal Constitucional y Politica Judicial. Profesor de la Facultad de Derecho y de la Maestría en Derecho Procesal de la USMP, así como de la Maestría en Derecho Procesal de la PUCP. Socio Principal y Director del Área de Litigación y Compliance del Estudio Javier Valle-Riestra, López Flores \& Munar, Abogados. 1lopez@jvr.pe 


\section{PRESENTACIÓN}

Este trabajo es de orden descriptivo. Procuro esquematizar el sistema de control constitucional en el Perú que se caracteriza, como bien lo señala nuestra doctrina nacional, por ser dual o paralelo (García Belaunde, 1998 , p. 147), puesto que coexiste el control difuso, oriundo de la experiencia anglosajona y americana (artículo $138^{\circ}$ de la Constitución); y el abstracto o concentrado, propio de la experiencia austriaca y eurocontinental (artículo $204^{\circ}$ de la Constitución).

La coexistencia de ambos modelos de control, en mi concepto, impulsa la necesidad de tener claro el sendero por donde cada uno transita. Por un lado, el control difuso muestra una operatividad auténticamente difuminada a nivel de toda la Magistratura, independientemente de la especialidad y del tipo de proceso que conozcan. Tal diversificación empuja a una toma de conciencia de los operadores jurídicos $\mathrm{y}$, además, a encontrar lazos comunicantes (y coherentes) con el Tribunal Constitucional, a quien la Constitución le ha conferido la labor de Supremo Contralor de la Constitucionalidad. Por otro lado, en esa misma tarea, cabe reconocer que el proceso de acción popular forma parte de la operatividad del modelo concentrado; sin embargo, este no ha sido diseñado por el Constituyente para ser supervigilado por el Tribunal Constitucional.

Por ello en este trabajo sostendré que el control constitucional en el Perú es un «modelo aún por armar» pero, sobre todo, por concientizar. La exploración del control de constitucionalidad servirá para precisar algunos aspectos conceptuales que lo vinculan con la interpretación constitucional de manera muy estrecha, a la luz no solo de los que sostiene la doctrina comparada actual, sino también de la jurisprudencia del Tribunal Constitucional.

\section{EL CONTROL CONSTITUCIONAL JURISDICCIONAL EN PERSPECTIVA COMPARADA}

En estos tiempos donde se aspira a que las democracias (sobre todo las latinoamericanas) se desenvuelvan en el paradigma del Estado constitucional, el control constitucional jurisdiccional constituye una herramienta esencial, fundamental, de control de los poderes políticos, concretamente del Legislativo.
En palabras de Fioravanti (2009):

Si la constitución debe ser-precisamente como acto de fundación de los derechos $y$ libertades - una verdadera y precisa norma jurídica -y no ya un mero manifiesto político-ideológico como sostenían los juristas liberales a propósito de las declaraciones de derechos de la revolución-, surge enseguida el problema de la ilegitimidad de aquellas normas de derecho positivo estatal vigentes en cuanto emanadas formalmente de manera correcta, pero contrarias a la Constitución - norma fundamental de orden superioren cuanto a los contenidos sustanciales. En otras palabras, la existencia misma de un control de constitucionalidad -no importa si difuso o concentrado, si de mera inaplicación de la norma estatal constitucionalmente ilegítima al caso concreto o con eficacia anulatoria erga omnes de la norma misma- destruye el dogma liberal-estatalista de la fuerza absoluta de la ley, y crea así una situación, inconcebible para la doctrina decimonónica, en la que la validez de las normas del Estado está como suspendida, en el sentido de que depende de un juicio sobre su conformidad con la constitución y, en definitiva, con una cierta interpretación de la Constitución y de los principios constitucionales. (p. 128)

El tránsito del paradigma del Estado de derecho al Estado constitucional se trata, sin duda alguna, de un cambio cultural: de pensar la Constitución para practicarla. Definitivamente, es fruto de lo acontecido en Europa occidental, específicamente como consecuencia de las dos guerras mundiales (Zagrebelsky, 2009). Si tuviésemos que pensar en algún hito históricopolítico común en Latinoamérica que permita ajustar nuestra brújula en dirección del Estado constitucional, creo que esta fue la celebración de la Convención Americana de Derechos Humanos (CADH) en 1969. Nuestro país abrazó la CADH recién en 1979 con la Constitución aprobada ese año.

Sin embargo, pretender vivir en un paradigma de resguardo y respeto absoluto a los derechos fundamentales en países latinoamericanos, y específicamente en el Perú, es aún una lucha, una carrera de resistencia. Digo todo esto en la medida de que, en materia de 
control constitucional, los modelos o sistemas «originarios», como el difuso y concentrado, respondieron a una manera de pensar y practicar las libertades.

El control difuso caló hondo en Latinoamérica a partir de la famosa sentencia de la Corte Suprema Federal Norteamericana pronunciada en 1803 en el caso Marbury vs. Madison. Sin embargo, como bien anota Bianchi (1992 pp. 52 y ss.), los antecedentes y fuentes de la doctrina empleada por el Chief Justice John Marshall en ese fallo se encuentran: $i$ ) en la sentencia del año 1610 pronunciada en Inglaterra por Sir Edward Coke, Chief Justice del Common Pleas en el conocido caso del médico Thomas Bonham; ii) en los debates de la Convención Constituyente de Filadelfia de 1787; iii) en los artículos de Alexander Hamilton en El federalista $\left(\mathrm{N} .{ }^{\circ} \mathrm{S} 78\right.$ y 82); y iv) en varios casos precursores pronunciados en las colonias norteamericanas inspirados en la doctrina del caso Bonham, que fuera dejada de lado en los tribunales ingleses con posterioridad a su dictado, pero bien recibida en dichas colonias ${ }^{1}$.

Debe quedar claro, entonces, que el caso Marbury vs. Madison es el referente de la revisión judicial de las leyes, pero no su fundador ${ }^{2}$.

1 Bianchi (1990) dice al respecto: "Pero lo que no tuvo frutos en la metrópoli, sí en cambio provocó intensa adhesión en las colonias. Los norteamericanos, del otro lado del océano, emplearon entusiastamente desde un comienzo los principios del judicial review elaborado por Coke. Asi, ya en el siglo xvII, en Giddings vs. Browne, el Justice Symonds de Boston, Massachusetts, dispuso que una ley positiva no podia estar en contra de la ley natural o fundamental. Esto fue repetido por James Otis, en el caso Paxton en 1761 y fue aplicado también por la Suprema Corte de Rhode Island en Trevett vs. Weeden en 1786, siendo esto reproducido por los Tribunales de Carolina del Sur en Bowman vs. Middleton en 1792. Puede decirse, en conclusión, que Coke elaboró una teoría que, si bien basada en precedentes medievales (principalmente del siglo xIv), implicaba una nueva formulación jurídica que Inglaterra y su Constitución no estaban preparados para recibir. Tal la causa de su rechazo. En cambio, si lo estaban los colonos norteamericanos. Para ellos, apunta Plucknett, el Parlamento inglés no era su héroe, sino más bien un cuerpo legislativo distante y poco simpático en el que no tomaban participación alguna». (pp. 58-59)

2 Es más, quince años antes de Marbury vs. Madison (1788) Alexander Hamilton, en la edición LXXVIII publicada en "El Federalista" (2014) expuso esta contundente argumentación: «El derecho de los tribunales a declarar nulos los actos de la legislatura, con fundamento en que son contrarios a la Constitución, ha suscitado ciertas dudas como resultado de la idea errónea de que la doctrina que lo sostiene implicaria la superioridad del Poder Judicial frente al Legislativo. Se argumenta que la autoridad que puede declarar nulos los actos de la otra necesariamente será superior a aquella de quien proceden los actos nulificados. Como esta doctrina es de importancia en la totalidad de las constituciones americanas, no estará de más discutir brevemente las bases en que descansa.
Y, por su parte, como bien señala Lombardi (2009: XXVI-XXVII), en el caso de Europa occidental, el planteamiento del problema de contar con una jurisdicción constitucional surge después de la Primera Guerra Mundial (1919), dado el notorio fracaso de atribuir al poder político un poder neutro en la tarea de garantizar el respeto de la Constitución. Es así que Han Kelsen propone la tesis de un Tribunal Constitucional en el Anteproyecto de la Constitución Austriaca de 1920, como así lo pone de manifiesto en su trabajo intitulado La garantía jurisdiccional de la Constitución (García Belaunde, 2008, p. 6) ${ }^{3}$ y que, posteriormente, en 1938, defiende en la polémica con Carl Schmitt (Lombardi, 2009, pp. 290 y ss.).

La tesis de Kelsen consistía en extraer la defensa de la Constitución de los

No hay proposición que se apoye sobre principios más claros que la que afirma que todo acto de una autoridad delegada, contrario a los términos del mandato con arreglo al cual se ejerce, es nulo. Por lo tanto, ningún acto legislativo contrario a la Constitución puede ser válido. Negar esto equivaldría a afirmar que el mandatario es superior al mandante, que el servidor es más que su amo, que los representantes del pueblo son superiores al pueblo mismo y que los hombres que obran en virtud de determinados poderes pueden hacer no solo lo que estos no permiten, sino incluso lo que prohíben.

$\mathrm{Si}$ se dijere que el cuerpo legislativo por si solo es constitucionalmente el juez de sus propios derechos y que la interpretación que de ellos se haga es decisiva para los otros departamentos, es lícito responder que no puede ser esta la presunción natural en los casos en que no se colija de disposiciones especiales de la Constitución. No es admisible suponer que la Constitución haya podido tener la intención de facultar a los representantes del pueblo para sustituir su voluntad a la de sus electores. Es mucho más racional entender que los tribunales han sido concebidos como un cuerpo intermedio entre el pueblo y la legislatura, con la finalidad, entre otras varias, de mantener a esta última dentro de los limites asignados a su autoridad. La interpretación de las leyes es propia y peculiarmente de la incumbencia de los tribunales. Una Constitución es de hecho una ley fundamental y asi debe ser considerada por los jueces. A ellos pertenece, por lo tanto, determinar su significado, así como el de cualquier ley que provenga del cuerpo legislativo. $\mathrm{Y}$ si ocurriere que entre las dos hay una discrepancia, debe preferirse, como es natural, aquella que posee fuerza obligatoria y validez superiores; en otras palabras, debe preferirse la Constitución a la ley ordinaria, la intención del pueblo a la intención de sus mandatarios". (p. 332)

3 En este texto reflexiona Kelsen: "El presente estudio trata el problema de la garantía jurisdiccional de la Constitución, denominada generalmente justicia constitucional, desde un doble punto de vista. Se expone, en primer lugar - cuestión teórica- la naturaleza jurídica de esta garantía fundándose, en última instancia, en el sistema sobre el cual el autor ha dado ya una explicación de conjunto en su "Teoría General del Estado" (Allgemeine Staatslehre, Berlin, 1925). El estudio busca luego - cuestión práctica- los mejores medios para realizarla: el autor se apoya en este aspecto en las experiencias que ha tenido después de varios años en su calidad de magistrado y ponente permanente del Tribunal Constitucional de Austria. En efecto, la Constitución austriaca, votada en 1920 sobre la base de un Proyecto elaborado por el autor a petición del Gobierno austriaco, ha dado a la institución de la justicia constitucional un desarrollo más completo que ninguna Constitución anterior". 
representantes del poder político y colocarla en manos de un órgano independiente de tal poder ${ }^{4}$. Sin embargo, los conflictos bélicos y la inestabilidad política propias del periodo de entreguerras no generaba un contexto propicio «para el desarrollo e, inclusive, la existencia misma de las instituciones constitucionales y sus instrumentos protectores» (Fix-Zamudio, 1968, p. 492).

Por ello, en Europa occidental, el término de la Segunda Guerra Mundial (1945) fue clave para el desarrollo de las instituciones procesales y la difuminación del modelo de control concentrado en la figura del Tribunal Constitucional. De esta manera, el surgimiento del paradigma del Estado constitucional determinó que sea inconcebible que la defensa de la Constitución esté en manos del poder político.

\section{UN BREVE REPASO HISTÓRICO PARA COMPRENDER LAS IDAS Y VUELTAS DEL CONTROL CONSTITUCIONAL EN EL PERÚ}

De acuerdo con Bernales (1998, p. 137), el contexto histórico y social de los pueblos latinoamericanos guardan lazos comunes al haber sido parte dominada del colonialismo europeo (España y Portugal). Por tanto, aún después de la independencia de los Estados formados sobre esas antiguas colonias, estos no fueron proclives al respeto y defensa de las libertades y los derechos humanos.

4 Sin embargo, es interesante la reflexión histórica planteada por Lombardi (2009: xxvII): "La construcción de Kelsen [...] se abstrae a cualquier concepto histórico-concreto de Constitución, y se encasilla en un mecanismo de garantía que se encuentra vinculado a un precedente cuyas raices se remontan a una institución que se halla fuera del constitucionalismo moderno. Se trata de una institución en realidad más emparentada con el ordenamiento del Antiguo Régimen que con el de la Restauración, por sus origenes en figuras que remontan su antecedente teórico más claro al llamado pouvoir d'intérination del Tribunal Supremo del Imperio (los en Francia llamados Parlamentos del Antiguo Régimen que podian bloquear la entrada en vigor de cualquier acto soberano sobre todo donde reinaba un rey absoluto). A este respecto, importa recordar que las competencias del viejo Tribunal del Imperio implicaban la posibilidad de establecer una cierta garantía de los derechos, si bien limitada y no del todo manifiesta, pero contemplaban desde luego la posibilidad de que un juez pudiera intervenir de algún modo en materia de derechos y garantias constitucionales. El Tribunal Constitucional propuesto por Kelsen en el texto de la recién establecida República austriaca inmediatamente después de la Primera Guerra Mundial, retrotrae, por consiguiente, sus antecedentes a las instituciones del Imperio $\mathrm{y}$, por ello, en principio no comportaba ningún tipo de reacción frente al pasado, no cuestionando la idea de Constitución hasta entonces imperante, ni significando reconsideración alguna del planteamiento general de las garantias constitucionales y su destino".
Por ello, según el mismo autor:

El proceso de formación de la conciencia $y$ de la identidad nacional fue 'lento y desigual', dado que no solo no existía Estado, sino que el referente próximo era una metrópoli lejana ubicada en el continente europeo, mientras que en nuestra región, ni siquiera se configuraba algo parecido a un régimen de autonomías parciales y sectorializadas [...]. Una primera hipótesis que surge de un contexto histórico-político como el sumariamente presentado, lleva a plantear la precaria vigencia de los derechos humanos en nuestro continente, con la existencia de una democracia insuficiente, retardada en el tiempo y afectada por las dictaduras. Como elemento derivado de esta situación, la condición ciudadana aparece como poco enraizada. Las carencias de vivencias ciudadanas a lo largo de la historia republicana de nuestros países afectó el ejercicio concreto de los derechos civiles y políticos, imponiendo una relación horizontal y exigente con el poder. (Bernales, 1998, p. 137)

En ese contexto histórico-político referido por Bernales, se dice que, con posterioridad a la independencia lograda por los pueblos latinoamericanos del yugo colonial instaurado por España y Portugal, los juristas de ese tiempo prestaron especial importancia al sistema constitucional de los Estados Unidos y que, en esa idea, cobraron fundamental importancia dos obras paradigmáticas: La democracia en América del Norte por Alexis de Tocqueville $\mathrm{y}$, posteriormente, las publicaciones de $E l$ federalista que contiene artículos periodísticos de Alexander Hamilton, James Madison y Jhon Jay (Fix-Zamudio, 1991, p. 17).

De esta manera, paulatinamente se produce un «trasplante» en las Constituciones latinoamericanas (empezando por la Constitución del Estado de Yucatán, México, de 1840), del control de constitucionalidad de las leyes establecido por la Constitución Norteamericana de 1787 y desarrollada por la jurisprudencia de la Suprema Corte Federal, pero con sus propios matices e importantes aportes (Fix-Zamudio, 1991, p. 18).

Así, las Constituciones latinoamericanas adoptan el habeas corpus y, en México, se crea 
el amparo, siendo este último su mayor aporte a aquello que se conoce hoy como Derecho Procesal Constitucional. No obstante, desde hace cuarenta años, se ha asentado el llamado modelo austriaco-kelseniano de control de la constitucionalidad, el mismo que, como bien anota Fernández Segado (1996, p. 237), en algunos ordenamientos de nuestras naciones latinas ha sufrido una variante: la creación de un Tribunal Constitucional, que únicamente ejerce la facultad de control concentrado, y, por otro, la conservación —simultánea o paralela-de la facultad de los jueces ordinarios de efectuar el control difuso de constitucionalidad de las leyes norteamericano con efectos interpartes. García Belaunde (2006, p. 23) señala que esos son los casos de Guatemala (1965 y 1985), Chile (1970 y 1980), Ecuador (1978) y Perú (1979), aunque a este listado habría que agregar el caso de Bolivia (1994).

En el caso peruano, el control de constitucionalidad de las leyes a cargo de órganos jurisdiccionales es una decisión claramente adoptada en la Constitución de 1979. En mi concepto, son tres las etapas del control constitucional en la historia del Perú republicano: la primera, de control político (inicios de la República hasta 1920); la segunda, de aproximación a un modelo jurisdiccional de control constitucional (1920 a 1979); y, finalmente, de un modelo jurisdiccional de control constitucional dual o paralelo (1979 hasta la fecha). Una posición distinta sostiene en nuestro medio Blume (2014, p. 242) $)^{5}$.

Al revisar las Constituciones del Perú la primera etapa de control político de la constitucionalidad se remonta a la primera Constitución de 1823, así como a las Constituciones de 1828, 1834, 1839, 1856, 1860,1867 y 1920 respectivamente, puesto que en todas ellas se estableció el deber de todo ciudadano de reclamar ante los poderes políticos (Legislativo y Ejecutivo)

\footnotetext{
5 Blume (2014, pp. 242 y ss) identifica estas tres etapas: (i) del control exclusivamente politico de las infracciones fácticas a la Constitución en la línea gaditana y los primeros atisbos del control normativo. 1821-1932; (ii) el control exclusivamente político de las infracciones fácticas a la Constitución y el control concentrado de constitucionalidad y de legalidad de normas infralegales a cargo del Poder Judicial. 1933-1935; y, (iii) el control exclusivamente político de las infracciones fácticas a la Constitución, el contro concentrado de constitucionalidad y de legalidad de normas infralegales a cargo del Poder Judicial y el control disperso de constitucionalidad en la modalidad americana 1936-1979.

6 He revisado los textos de las Constituciones del Perú del siglo XIX y xx contenidas en la obra de Garcia Belaunde (2006).
}

la inobservancia de las disposiciones constitucionales ${ }^{7}$. Es preciso mencionar que, en esta gama de Constituciones, la de 1856 fue la que en el artículo $10^{\circ}$ dispuso que resultaba « (...) nula y sin efecto cualquiera ley en cuanto se oponga a la Constitución».

Pese a que esta disposición constitucional no estableció la vía a través de la cual se declaraba tal nulidad ni tampoco quién sería el órgano competente para hacerlo, su aplicación quedó en el mundo de lo hipotético, dada la breve vigencia de la Constitución de 1856. Por el contrario, las Constituciones posteriores de 1860, 1867, 1920 y 1933, respectivamente, no la contemplaron, con lo cual este primer intento de control constitucional de las leyes cayó en el vacío.

La segunda etapa, en mi concepto, surge desde 1920. Y es que el control constitucional normativo jurisdiccional es aludido por Arenas y Loayza (1925, p. 102) en un discurso de orden pronunciado en el Colegio de Abogados de Lima, a propósito del homenaje rendido a la Corte Suprema por sus cien años de vida institucional. Este jurista señaló que había un «precedente legislativo» para institucionalizar el control difuso de constitucionalidad de las leyes. Dado que este discurso fue pronunciado en el año 1925, es probable que esté refiriéndose a los siguientes datos históricos aportados por Blume (2014):

[E]n 1923; año en el cual la Comisión Reformadora del Código Civil debate, a propuesta del jurista A. Solf y Muro, la inclusión en su Título Preliminar de una norma que habilitara el control disperso. Dicha propuesta fue debatida en la Sesión N. ${ }^{\circ} 21$, llevada a cabo el miércoles 28 de febrero de 1923, en cuya acta, por las intervenciones del proponente y de los señores Juan José Calle, M. A. Olaechea y Pedro M. Oliveira, se puede apreciar que el control disperso de constitucionalidad, creado a partir de su primer antecedente

7 El artículo $187^{\circ}$ de la Constitución de 1823 decía: "Todo peruano debe reclamar ante el Congreso, ante el Poder Ejecutivo, o ante el Senado la observancia de la Constitución, y representar fundadamente las infracciones que notare". Con similar texto, las Constituciones de 1828 (articulo $174^{\circ}$ ), 1834 (artículo $165^{\circ}$ ), 1839 (artículo $176^{\circ}$ ) y 1856 (artículo $14^{\circ}$ ) establecian el mismo deber ciudadano. Sin embargo, el artículo $13^{\circ}$ de la Constitución de 1860 , el artículo $12^{\circ}$ de la Constitución de 1867 y el artículo $16 .^{\circ}$ de la Constitución de 1920 , respectivamente, establecieron que esa reclamación, además de ser planteada ante los poderes políticos, podía formularse "ante cualquier autoridad competente" ". 
constituido por el caso Marbury versus Madison, plantaba sus primeras raices en el Perú y que ya existía conciencia de la importancia y trascendencia del control disperso de constitucionalidad, aunque con cierta reserva, expresada a través de las reflexiones de los señores Solf y Olaechea; tanto es así, que este último sostenía la tesis de reservar ese control solo a la Corte Suprema, por considerar excesivo que el mismo fuera ejercido por jueces inferiores. No obstante esta reserva, al final se impuso el criterio de señalar el principio y dejar para una reglamentación posterior la regulación especifica del trámite a seguir para el cabal ejercicio del control en cuestión. Ello fluye del debate producido en la Sesión No. 23, del miércoles 14 de marzo de 1923, entre los señores Calle, Olaechea, Oliveira y Solf. (p. 249)

Sin embargo, hay un dato por demás curioso y de singular importancia que registra el discurso de orden de Arenas y Loayza (1925): la existencia de un antecedente jurisprudencial de control difuso de constitucionalidad en el Perú, expedido cinco años antes de pronunciar dicho discurso. En efecto, señala que dicha modalidad de control:

Cuenta con un precedente judicial en la ejecutoria suprema del 26 de agosto de 1920, sobre hábeas corpus que reprodujo los fundamentos del dictamen fiscal del doctor Seoane en que se afirmaba que, en caso de contradicción entre la Constitución y la ley, prevalecía la primera (página 430 del tomo 2o. de sus dictámenes fiscales). (p. 102)

Pese a estas aproximaciones legislativas y jurisprudenciales registradas por Arenas y Loayza, el control constitucional de las leyes en sede jurisdiccional no llegó a cristalizarse.

En efecto, derrocado el oncenio de Leguía, en 1931 se instauró un Congreso Constituyente con el propósito de hacer una nueva Constitución. Así, David Samanez Ocampo, Presidente de la Junta Nacional de Gobierno, mediante Resolución Suprema del 7 de agosto de 1931, designó al jurista Manuel Vicente Villarán para que presidiera una comisión encargada de elaborar un anteproyecto de Constitución que sirviera de referencia para el Congreso Constituyente de 1931.
Lamentablemente, el Congreso Constituyente de 1931 dejó de lado el anteproyecto de Constitución elaborado por la Comisión Villarán. Como bien anota Paniagua (2004, pp. 422-423), al igual que la asamblea de 1919, dicho Congreso Constituyente «resultó tributario de las violentas pasiones que agitaron a los grupos políticos que se enfrentaron en el proceso electoral [siendo que] sus enconos e intereses de coyuntura les impidieron apreciar debidamente el valor de sus aportes».

Así, se desechó la propuesta contenida en el artículo $142^{\circ}$ del referido anteproyecto por el cual se declaraban:

\section{Inaplicables las leyes contrarias a la Constitución, limitando esa inaplicabilidad a los casos sometidos a su conocimiento; $y$ en todos los casos en los cuales se declarara, en primera o segunda instancia, sobre la inconstitucionalidad de una ley, la Corte Suprema debería revisar en Sala Plena esos pronunciamientos. La declaración sobre la anticonstitucionalidad de una ley debería adoptarse por las dos terceras partes del pleno de la Corte Suprema y regiría exclusivamente para el caso particular en el cual hubiera sido dictada. (García Calderón Koechlin, 1973, p. 412)}

El Congreso Constituyente de 1931 aprobó la Constitución de 1933 en cuyo artículo $133^{\circ}$ permitía el control de constitucionalidad de disposiciones normativas infralegales por parte del Poder Judicial vía acción popular ${ }^{8}$. Sin embargo, durante la vigencia de esta Constitución, nada más y nada menos que en el Código Civil de 1936 se consignó el artículo XXII del Título Preliminar, cuyo texto decía: «Cuando hay incompatibilidad entre una disposición constitucional y una legal, se prefiere la primera». Dicho texto normativo fue fruto de la propuesta hecha trece años antes en el seno de la Comisión Reformadora del Código Civil. (Blume, 2014, p. 249)

Sin embargo, tanto el artículo $133^{\circ}$ de la Constitución de 1933 como el artículo xXII del Título Preliminar del Código Civil de 1936

8 Constitución Política del Perú de 1933

"Artículo 133. ${ }^{\circ}$. Hay acción popular contra los reglamentos y contra las resoluciones y decretos gubernativos de carácter general que infrinjan la Constitución y las leyes, sin perjuicio de la responsabilidad política de los ministros.

La ley establecerá el procedimiento judicial correspondiente". 
tuvieron un desarrollo normativo recién el 26 de julio de 1963, fecha en la que se dictó el Decreto Ley N. ${ }^{\circ} 14605$ (Ley Orgánica del Poder Judicial). Se reguló el procedimiento tanto de la acción popular de control constitucional y legal de normas infralegales (artículo $7^{\circ}$ ) como de aplicación del control difuso de normas legales (artículo $8^{\circ}$ ).

A pesar de que en 1925, al hacer un recuento jurisprudencial de importantes fallos de la Corte Suprema, Arenas y Loayza (1925, pp. 99-100) destacó las decisiones del Alto Tribunal en materia de garantías individuales durante sus cien primeros años ${ }^{9}$, García Calderón (1973, pp. 396-399) refiere que, como consecuencia de que la Constitución de 1920 permitía que un vocal titular de la Corte Suprema pueda ejercer el cargo de Ministro de Estado ${ }^{10}$, se presentaron dos casos de habeas corpus en 1920 en los que fueron protagonistas don Germán Leguía y Martínez (elegido en 1912 para ocupar una vocalía en la Corte Suprema) y el Presidente de la Corte Suprema, don Carlos Eráusquin.

Leguía y Martínez, siendo magistrado de la Corte Suprema, ocupó el cargo de ministro de Gobierno y presidente del Consejo de Ministros, protagonizando escenarios de tensión con el pleno de la Corte Suprema, primero, a propósito del decreto del 27 de mayo de 1920 sobre la expulsión de extranjeros perniciosos, y luego, por un habeas corpus interpuesto por algunos detenidos políticos en noviembre del mismo año.

El decreto del 27 de mayo de 1920, además de ordenar la expulsión, declaró la improcedencia del habeas corpus y dispuso que «las autoridades de policía se abstuvieran de obedecer y cumplir los mandatos de los tribunales y juzgados». El

9 Dijo al respecto: "La Corte Suprema siempre amparó en sus fallos las garantías individuales, desde la ejecutoria de 1865, declarando que el gobierno había cometido despojo clausurando la imprenta de 'El Perú' (Paz Soldán, vistas fiscales). O aquella en que ordenaba en 1872 que se restituyese a su dueño la posesión de la imprenta de 'E Nacional' (anales de ese año), hasta las ejecutorias recientes sobre 'hábeas corpus', en que la Corte declaró fielmente el derecho, llevando sus quejas hasta el Poder Legislativo, pero evitando con extralimitaciones de su parte, crear mayores conflictos. Y aquí debo detenerme, porque lo actual, lo palpitante, pertenece a la politica, que no ha de venir con sus nublados a oscurecer la limpidez de este ambiente ni a turbar la serenidad de esta hora y la majestad de este homenaje".

10 Constitución Politica del Perú de 1920

"Artículo 149. ${ }^{\circ}$. Los miembros del Poder Judicial no podrán ser nombrados por el Poder Ejecutivo para desempeñar ningún cargo político, exceptuándose a los Magistrados de la Corte Suprema que podrán ser nombrados Ministros de Estadon. ministro Leguía y Martínez sustentó la emisión del decreto en la falta de una ley de extranjería. La Corte Suprema, presidida por don Carlos Eráusquin, emitió un pronunciamiento señalando que la ausencia de dicha ley no podía autorizar la suspensión de las garantías individuales ni afectar la independencia del Poder Judicial. En el segundo caso, el Ministro Leguía y Martínez sostuvo que los habeas corpus presentados por presos políticos «carecían de objeto en razón de haberse solicitado al Congreso el nombramiento de un juez ad hoc, apoyándose en el artículo $36^{\circ}$ de la Constitución, que facultaba al Congreso para dictar en casos extraordinarios en que peligrase la seguridad interior o exterior del Estado, las leyes y resoluciones especiales que demandase su defensa» (García Calderón, 1975, p. 398). La Corte Suprema, presidida por Carlos Eráusquin, cuestionó dicha posición «repudiando el pretendido nombramiento de jueces extraordinarios que no autorizaba el expreso tenor ni la génesis del invocado artículo $36^{\circ}$ [de la Constitución]» (ibídem, p. 399).

Estos serios indicios de debilidad institucional del Poder Judicial con relación a la influencia del poder político se ponen de manifiesto en otro célebre caso acontecido en 1955: el pretendido retorno al Perú del expresidente José Luis Bustamante y Rivero a través de un habeas corpus.

Bustamante y Rivero fue desterrado en 1948 luego de un golpe militar. Mientras vivía en Ginebra en 1955 escribió un Manifiesto a la Nación peruana ante la proximidad de las elecciones, expresando su voluntad de regresar al Perú. Inmediatamente, sus allegados y correligionarios planificaron la presentación de un habeas corpus con ese propósito que fue interpuesto por su apoderado, el Dr. Luis Bedoya Reyes.

La polémica del caso consistió en que el artículo $67^{\circ}$ de la Constitución de 1933 disponía el libre ingreso en el territorio nacional «con las limitaciones que establezcan las leyes penales, sanitarias y de extranjería». En ese sentido, la Ley N. ${ }^{\circ} 11049$, Ley de Seguridad Interior de la República, otorgaba facultades al Ministerio de Gobierno para aplicar las medidas necesarias que impedían el ingreso al país.

El 25 de noviembre de 1955, el Segundo Tribunal Correccional de la Corte Superior de Lima falló, por mayoría, declarando la 
improcedencia del habeas corpus interpuesto a favor de Bustamante y Rivero. El magistrado Domingo García Rada votó en contra de la posición mayoritaria, dándole la razón al favorecido y señalando lo siguiente:

Examinando la ley once mil cuarenta y nueve aparece lo siguiente: que el artículo 31 concede amplias facultades al Ministerio de Gobierno y Policía para prevenir, la comisión de los delitos contemplados en los artículos primero y segundo para cuyo juzgamiento crea organismos judiciales, que constituyen fuero privativo, y establece un procedimiento especial que es materia del capítulo quinto. De lo anterior resulta que el conocimiento y juzgamiento de los delitos contra la seguridad y tranquilidad de la República y contra la Organización y Paz Interna de la República, corresponde a un fuero privativo cuya existencia autoriza la Constitución en el artículo doscientos veintinueve.

Pero para estar sometido a fuero privativo se requiere proceso, y habiendo declarado el señor Ministro de Gobierno que el doctor Bustamante y Rivero no se encuentra procesado es del caso deducir, que faltando el emplazamiento ante la autoridad respectiva, el referido doctor Bustamante no se encuentra comprendido dentro de los alcances de la ley especial denominada de Seguridad Interior de la República. [...]

No estando comprendido el caso subjudice dentro de los alcances precisados de la Ley especial de Seguridad Interior de República, debe entenderse que los preceptos constitucionales que garantizan el derecho al libre tránsito en el territorio de la República tienen pleno vigor. (García Rada, 2004, p. 203)

Nótese que, en este voto en discordia, el razonamiento empleado por García Rada no gira en torno a la aplicación del control difuso de constitucionalidad de la Ley de Seguridad Interior de la República («LSIR»), ya que dicho magistrado no cuestionó tal constitucionalidad. Por el contrario, lo que señaló fue que los hechos contenidos en el caso concreto de Bustamante y Rivero no se subsumían en los alcances de dicha ley y, por ende, no podía restringírsele su libre acceso al territorio nacional. Preciso esto pues la cuestión sobre la constitucionalidad de la LSIR era un asunto que en ese momento estaba en el debate público.

Una nota periodística del diario La Prensa del 25 de noviembre de 1955, al comentar el fallo dictado por el Segundo Tribunal Correccional de Lima, decía que «la inconstitucionalidad [de la LISR] ha sido insistentemente señalada por la opinión. Recientemente, el Primer Congreso Nacional de Abogados la declaró anticonstitucional, antijurídica $y$ antidemocrática». (García Rada, 2004, p. 202)

Para efectos de lo que concierne a la debilidad institucional del control difuso en el Perú, el fallo de la Corte Suprema - pronunciado a propósito del recurso de nulidad planteado en el trámite de este habeas corpus de Bustamante y Rivero - muestra la genuflexión de los jueces ante el poder político en la época en mención. $\mathrm{Y}$ es que en el fallo pronunciado el 7 de enero de 1956, la Corte Suprema dijo lo siguiente sobre la facultad de control difuso de constitucionalidad establecido en el artículo XXII del Título Preliminar del Código Civil, cuya aplicación se invocó para inaplicar la LISR al caso concreto de Bustamante y Rivero:

Que el artículo veintidós del Título Preliminar del Código Civil, en que se pretende sustentar la facultad judicial para no aplicar las leyes, no puede regir sino en el campo restringido del Derecho Civil, ya que dicho Código no es un Estatuto Constitucional, sino una ley que norma las relaciones de la vida civil, en cuyas controversias cuando interviene el Estado, lo hace como sujeto de derecho privado, sin que ninguna disposición legal posterior haya extendido su aplicación a otros órdenes del campo jurídico, en que aquel actúa como sujeto de derecho público; que para que el Poder Judicial pudiera aplicar la facultad que se le atribuye, seríanecesarioque ella emergiera consignada en forma expresa o inequívoca en precepto de la propia Constitución, formando parte del derecho constitucional positivo como acontece en los contados países cuyas Cartas Fundamentales consagran tal prerrogativa; que nuestra Constitución Politica crea y organiza los Poderes Públicos, señala sus atribuciones $y$ delimita su funcionamiento, con el fin de que, actuando cada cual dentro de su 
propia órbita, concurran a realizar los fines superiores del Estado, estructura en la que no se consagra la facultad del Poder Judicial para declarar la inconstitucionalidad de una ley, que es la forma más amplia de participar en la función legislativa, la que, en cuanto a este Poder se refiere, está restringida por el artículo ciento veinticuatro de la Constitución, a la iniciativa de sus miembros en materia judicial, ejercitada por intermedio de la Corte Suprema. (García Rada, 2004, p. 208)

La tercera etapa que denomino de control constitucional jurisdiccional surge en 1979 con la apuesta clara y decidida de la Constitución, aprobada ese año, de apostar por un modelo de control constitucional jurisdiccional dual o paralelo. Y es que el artículo $236^{\circ}$ otorgó la facultad al juez de preferir la norma constitucional frente a la legal y, en ese orden jerárquico, a la norma legal frente a las de menor rango, en caso de incompatibilidad. Asimismo, en el inciso $1^{\circ}$ del artículo $298^{\circ}$ reguló la acción de inconstitucionalidad como una de las llamadas garantías constitucionales e instituyó el ejercicio del control abstracto de constitucionalidad a cargo de un órgano ad hoc, propio del modelo austriaco-kelseniano, denominado Tribunal de Garantías Constitucionales (TGC), cuyo efecto de la sentencia que declarase fundada la demanda sería derogar la norma acusada de inconstitucional.

Al respecto, Eguiguren y García Belaunde (2008) señalan lo siguiente:

Ya Brewer-Carías precisaba que la tendencia predominante en América Latina ha sido la evolución hacia el establecimiento de un «sistema mixto», agregando posteriormente al control difuso el sistema concentrado radicado, en unos casos, en la Corte Suprema o, en otros, en tribunales constitucionales; funcionando ambos simultáneamente, o adoptando —en el caso de algunos países-desde el principio dicho modelo mixto. Sin embargo, como precisa uno de los autores, puede hacerse una distinción al interior de estos modelos «derivados», diferenciando al modelo "mixto» de otro que se puede denominar «dual o paralelo», que correspondería al sistema de jurisdicción constitucional vigente en el Perú. Si bien ambos surgen por la incorporación de elementos del modelo concentrado o europeo en países que ya tenían adoptado (y mantienen) el sistema americano o difuso, el sistema mixto se genera cuando se produce una mezcla de elementos constitutivos de los dos modelos clásicos, que dan lugar a un «tercero» que no es lo que son los dos anteriores pero tampoco algo enteramente autóctono $y$ original. En cambio, el modelo dual o paralelo es aquel que existe cuando en un mismo país, en un mismo ordenamiento jurídico, coexisten el modelo americano y el modelo europeo, pero sin mezclarse, deformarse ni desnaturalizarse. $Y$ esto, que no es frecuente, tiene su partida de nacimiento en la Constitución peruana de 1979. (p. 380)

No obstante, hay autores como Sar (2014, p. 844-845) que discrepan con esta calificación del modelo peruano de dual o paralelo ${ }^{11}$.

Ahora bien, el funcionamiento del Tribunal de Garantías Constitucionales no fue satisfactorio. Morales (2000, p. 72) señala que los miembros del TGC no dieron muestras, salvo honrosas excepciones, de independencia respecto de los otros poderes del Estado; quizás por el sistema de nombramiento que se había diseñado (tres miembros eran elegidos por el Poder Legislativo, tres por el Poder Ejecutivo y tres por el Poder Judicial), como por la misma actitud personal de los magistrados, con lo que se reproducía lo que ocurría con el Poder Judicial. Así, la falta de independencia trajo consigo una paupérrima producción jurisprudencial, en lo que se refiere a las demandas de inconstitucionalidad de leyes, percibiéndose una disposición a no declarar la inconstitucionalidad para no perturbar la acción política de los partidos gobernantes de turno.

\footnotetext{
11Dicho autor sostiene que las competencias del Tribunal Constitucional no concuerdan exactamente con las del modelo europeo ya que no posee, por ejemplo, capacidad para autoplantearse la cuestión de constitucionalidad cuando resuelve procesos de amparo, pudiendo tan solo recurrir al ejercicio del control difuso, además que el precedente que orienta la actuación de los órganos inferiores en el sistema norteamericano proviene de la máxima instancia de ese poder del Estado diseñado por el artículo tercero de su Constitución. En cambio, en nuestro ámbito, el precedente constitucional emana del Tribunal Constitucional a tenor de lo que dispone el artículo vir del Título Preliminar del Código Procesal Constitucional.
} 
Desde el punto de vista institucional, la Constitución de 1979 contempla, por primera vez, el proceso de amparo y ratifica la vigencia del habeas corpus ${ }^{12}$.

Por su parte, la Constitución de 1993 ha conservado el denominado modelo dual de control constitucional jurisdiccional. El artículo $138 .^{\circ}$ de la Constitución contempla la facultad-deber de los jueces de observar la supremacía constitucional sobre el resto de normas del ordenamiento jurídico y de las legales sobre las de menor jerarquía, y así sucesivamente; mientras tanto, el artículo $201 .^{\circ}$ de la Constitución contempla la figura del denominado Tribunal Constitucional, que tiene competencias para conocer: los procesos constitucionales de amparo, habeas corpus, habeas data y cumplimiento, cuando las demandas han sido denegadas en segunda instancia; el proceso de inconstitucionalidad (control concentrado); y los procesos competenciales (conflictos de competencia entre órganos constitucionales).

La elección de los miembros del Tribunal Constitucional es de carácter político, dado que los elige íntegramente el Parlamento.

El Tribunal Constitucional inició su funcionamiento en 1996; sin embargo, el gobierno dictatorial fujimorista destituyó a tres de los siete magistrados ese mismo año. Así, el tribunal ejerció sus funciones constitucionales sin posibilidad de conocer y decidir los procesos de inconstitucionalidad de las leyes.

Con la recuperación de la democracia en el 2001 se recompuso el Tribunal Constitucional (TC), y desde ese tiempo podemos decir que, con sus aciertos y yerros, existe producción jurisprudencial que ha venido a desarrollarse no solo por el activismo del TC, sino también por las herramientas procesales aportadas por el Código Procesal Constitucional dictado en el 2004 que coadyuvan a ese propósito.

12 Los datos históricos registran que el habeas corpus se creó en una ley de 1897. Sin embargo, su reconocimiento constitucional se produjo, por primera vez, en la Constitución de 1920 , específicamente en el artículo $24^{\circ}$ (habeas corpus por "prisión indebida"). Y en la Constitución de 1933, en el artículo $69^{\circ}$, se amplió el margen de acción de este proceso constitucional a "todos los derechos individuales y sociales reconocidos por la Constitución", es decir, el habeas corpus asumió una cobertura amplia para todos los derechos más allá del molde conceptual doctrinario y de aquel establecido en la Constitución de 1920 que lo incorporó por primera vez en el ordenamiento jurídico peruano.
Así, puede hablarse de dieciséis años de jurisprudencia constitucional del TC en treinta y ocho años de jurisdicción constitucional en el Perú, en una práctica que hace esfuerzos (y que muchas veces cae presa de la tensión) por aproximarse al paradigma del Estado constitucional. Sin embargo, es joven y aún inmadura nuestra cultura de control constitucional. Por eso afirmo que se trata de un modelo aún en formación, aún «por armar».

\section{CONTROL CONSTITUCIONAL E INTERPRETACIÓN}

\section{El control constitucional como efecto de la interpretación constitucional}

Uno de los debates intelectuales más sonados en la historia del derecho constitucional es el de Kelsen y Schmitt sobre la justicia constitucional. Como bien anota Lombardi (2009: XI):

[...] el punto de contraste fundamental
sobre el que gravita toda la polémica gira
en torno a la figura o, mejor dicho, al
órgano o institución, a que debe atribuirse
la facultad y la obligación de defender
o de salvar la Constitución, frente a los
diferentes tipos de violaciones posibles que
ponen en jaque su destino existencial y su
vigencia temporal. En este sentido, Kelsen
y Schmitt coinciden en la conveniencia
o necesidad de reconocer la figura del
defensor, del vigilante o del garante de la
Constitución, eso sí, condicionándolo a
su propio y particular concepto de Estado
y de Constitución, de manera que media
siempre una relación directa entre defensa
de la Constitución y concepto de la misma.

Pese a las posturas disonantes y opuestas de Kelsen y Schmitt, nótese que ambos coinciden en la necesidad de defender la Constitución. Y es que, como bien anota Bianchi (1992, p. 26), existe un absoluto consenso respecto a que la Constitución es la Ley Suprema. La cuestión fundamental radica en su cumplimiento, para lo cual se requiere «escoger los medios adecuados». Por ello, agrega este jurista argentino: "Aquí es donde aparece y se evidencia la necesidad de contar con un sistema efectivo de control de constitucionalidad que es, como puede verse, el más importante de los puntos del derecho constitucional». 
De lo dicho, surge una lógica conclusión: el control constitucional es el instituto sistémico destinado a buscar, del modo más eficaz, el cumplimiento cabal de la Constitución. De allí que se discuta a quién le corresponde esa tarea y a través de qué instrumentos, sin que ello signifique que este planteamiento instrumental del control se entienda como disociado de una teoría - como la que plantea Aragón Reyes (2002, pp. 120-121) — que lo concibe como parte del concepto mismo de Constitución ${ }^{13}$.

En esta línea argumentativa, resulta clave lo que señala Diego Valadés, citado por Canosa Usera (2013, p. 253): «por definición, controlar el poder es un acto de poder». En ese sentido, es tautológico afirmar que controlar el cumplimiento de la Constitución es un acto de poder. Y, como bien agrega Canosa Usera (2013):

La Constitución, amén de ser la norma cimera del ordenamiento, en el sentido kelseniano, es también, y en eso tenía razón Schmitt, la decisión política fundamental. Si es verdad lo anterior, el control de constitucionalidad, donde se despliega la interpretación del Tribunal Constitucional, no se limita a la fijación técnica de la norma sino que, al acometer esta tarea, delimita también los espacios de decisión política de los poderes constituidos. Es el intérprete supremo quien traza los límites que estos poderes no pueden desbordar y que vienen establecidos en la Constitución, o que más bien determina el alto tribunal al interpretarla». (p. 253)

Nótese que el control constitucional, como acto de poder, discurre a través de la interpretación constitucional. En este extremo, comparto plenamente el parecer de Blume Fortini (1996) cuando afirma que la interpretación

\footnotetext{
13 Dice Aragón Reyes: " [...] para la teoría de la Constitución el fenómeno del control [...] escapa al corsé de una única definición conceptual, pero ello no significa que posea una pluralidad de sentidos. Por el contrario, es justamente la existencia de un sentido "constitucionalmente" univoco del control lo que le permite ser [...] elemento inseparable de un concepto univoco de Constitución. Unidad de sentido que se deriva, pues, de la teoria de la Constitución, pero también de la misma teoria del control: Considerada la íntima relación que existe entre Constitución y control, parece evidente que la teoria de aquella ha de incluir a la teoría de este y que, a su vez, cualquier intento de teorización del control ha de dotar a este de un sentido univoco que sea capaz de englobar coherentemente las variadas formas que el control adopta en el Estado constitucional. Tal sentido no es otro que el de considerar al control como el vehículo a través del cual se hacen efectivas las limitaciones del poder".
}

constitucional es consustancial al análisis de constitucionalidad, le es inherente, forma parte de aquel, al punto en que «no puede haber análisis de constitucionalidad sin interpretación constitucional». (p. 326)

En efecto, un ejemplo muy claro y didáctico que muestra cómo la interpretación constitucional es inherente al control constitucional es el criterio que empleó el TC en el fundamento $12^{\circ}$ de la STC N. ${ }^{\circ}$ 0002-2009-PI/TC (caso TLC con Chile) donde dijo lo siguiente:

\section{2. [...] al Tribunal Constitucional le corresponde realizar una interpretación de los distintos significados de la norma impugnada para establecer si al menos una de ellas es conforme a la Constitución, antes de declarar su inconstitucionalidad literal. De modo que, a menos que una interpretación del artículo impugnado del ALC PERÚ-CHILE sea compatible con el artículo $54^{\circ}$ de la Constitución, la declaración de inconstitucionalidad cederá a la declaración interpretativa conforme a la Constitución. Por ello, es pacifico en la jurisprudencia constitucional que no toda declaración de inconstitucionalidad acarree la nulidad de la disposición normativa, no obstante no ser compatible con la Constitución, sino que requerirá para mantener su vigencia una interpretación de ser posible conforme a la Constitución.}

Como bien anota Canosa Usera (2013): «la interpretación constitucional es un formidable mecanismo de control del poder para asegurar que este se someta a la Constitución» (p. 256). Es decir, la labor de contrastar disposiciones legales con las constitucionales debe esforzar al intérprete a encontrar sentidos compatibles con la Constitución. Si esa búsqueda es infructuosa y la antinomia es inevitable, solo en esos casos el intérprete sostiene la incompatibilidad constitucional y, por ende, no hay otra vía que la invalidez de la disposición infractora ${ }^{14}$.

\footnotetext{
$14 \mathrm{Al}$ respecto, el "control de validez constitucional" en estricto ha sido definido por el Tribunal Constitucional en el fundamento $2 .^{\circ}$ de la STC N. ${ }^{\circ}$ 0004-2004-AI/TC de la manera siguiente [negrita y subrayados agregados]: "2. (...) La validez en materia de justicia constitucional, en cambio, es una categoría relacionada con el principio de jerarquia normativa, conforme al cual la norma inferior (v.g. una norma con rango de ley) será válida solo en la medida en que sea compatible formal y materialmente con la norma superior (v.g. la Constitución)".
} 
Así las cosas, puedo lanzar una primera conclusión de lo dicho hasta el momento: el control constitucional es un acto de poder puesto que controla el poder que emana de la Constitución. Y entre Constitución y control existe una visión unívoca porque es imposible concebir la Constitución sin mecanismos de control para su cumplimiento.

Pero, por otro lado, el instrumento de control constitucional es la interpretación constitucional, es decir, aquella operación por la cual, como bien señala Moreso (2014, pp.157158), está destinada a determinar el significado de las disposiciones constitucionales, esto es, de sus textos $\mathrm{y}$, más precisamente, determinar cuáles son lo que él denomina las «normas» de la Constitución (interpretación de dichos textos). Esta perspectiva conduce a este jurista a la tesis de la Constitución semántica, es decir, aquella que resulta de un conjunto de significados del texto constitucional que permiten entender la primacía de la Constitución. Este prestigioso jurista (2014) concluye: «sería más bien extraño afirmar que un texto de símbolos no interpretados disfruta de primacía. La idea de primacía sintáctica es incomprensible». (p. 158)

Por ello, entre la interpretación de la Constitución y el control de esta existe una relación de causa a efecto. Es imposible concebir el control constitucional sin un acto de interpretación constitucional previo. En esa lógica, la interpretación constitucional es un acto de poder, uno de control del poder, tesis a la que se adhieren los juristas españoles que antes he citado (Aragón Reyes y Canosa Usera).

\section{¿Control constitucional sobre las disposiciones juridicas o sobre sus sentidos interpretativos?}

Guastini distingue «interpretación» de «aplicación» de la Constitución. El primero, afirma el maestro italiano, puede hacerlo cualquiera; sin embargo, por «intérprete de la Constitución» habría que entender a aquel que aplica el texto constitucional y que se encuentra «calificado» para ello, es decir, que goza de competencia constitucional para dicha tarea ${ }^{15}$. Aquí, entonces, la cuestión trasunta

15 Transcribo in extenso lo que señala Guastini, dada su notable importancia:

"¿Quiénes son los intérpretes de la Constitución? Evidentemente, la pregunta está mal planteada. Intérprete del medio para controlar la Constitución a un aspecto más orgánico: quién debe realizarla y a través de qué vía.

Desde luego, en el debate Kelsen-Schmitt antes citado se discutía a quién le correspondía la labor de defensa de la Constitución. Por tanto, sobre la base de todo lo analizado en el numeral anterior, puede decirse que el debate giraba en torno a quién estaba «calificado» para asumir dicha labor de intérprete constitucional, por un lado, y, por otro, sobre qué vía emplear para ejercer esa labor interpretativa constitucional que conduce al control de constitucionalidad.

Al respecto, en nuestro medio, García Belaunde (1998, pp. 139-140) señala que la «jurisdicción constitucional» es el conjunto de mecanismos procesales destinados a defender la Constitución, sea en su aspecto orgánico o el dogmático, y que, conforme a la literatura especializada, se denominan modelos $\mathrm{o}$ sistemas de jurisdicción constitucional a la formas, usos, estilos o estructuras existentes para analizar, procesar y resolver los problemas que plantea la Constitución y su defensa. Así, agrega este autor que la caracterización de los modelos como «concentrado» y «difuso» se debe a Carl Schmitt, entendiendo al último de raigambre norteamericana $\mathrm{y}$, al primero, europeo continental, además del modelo político de cuña francesa. Allí, adviértase que la cuestión trasunta en que los facultados para ejercer la interpretación-control constitucional son los jueces o el Tribunal Constitucional, por un lado, o el Parlamento, en el modelo de control político francés, por otro.

No obstante, para poner las cosas en su lugar, creo indispensable hacer un alto en este análisis para mostrar el gráfico siguiente:

de la Constitución -como, por otra parte, de cualquier otro documento (normativo y no) - es todo aquel que la lea y se pregunte por su significado.

Bien vistas las cosas, cuando se habla de "intérpretes" de la Constitución, a lo que se alude no es a la interpretación del texto constitucional, sino, más bien, a su aplicación. Ya que todos pueden interpretar la Constitución, pero no todos pueden aplicarla (dicho sea de paso, esta tendencia a confundir interpretación y aplicación del derecho es un defecto que afecta un tanto a toda la teoría común de la interpretación).

Por lo tanto, lo que se quiere saber no es quiénes son los intérpretes de la Constitución, sin ulterior especificación, sino más bien quiénes son sus intérpretes "calificados" o "privilegiados" - Kelsen habría dicho, sus intérpretes "auténticos" - vale decir, los órganos competentes para aplicarla y, más específicamente, para decidir en última instancia el significado del texto constitucional". 


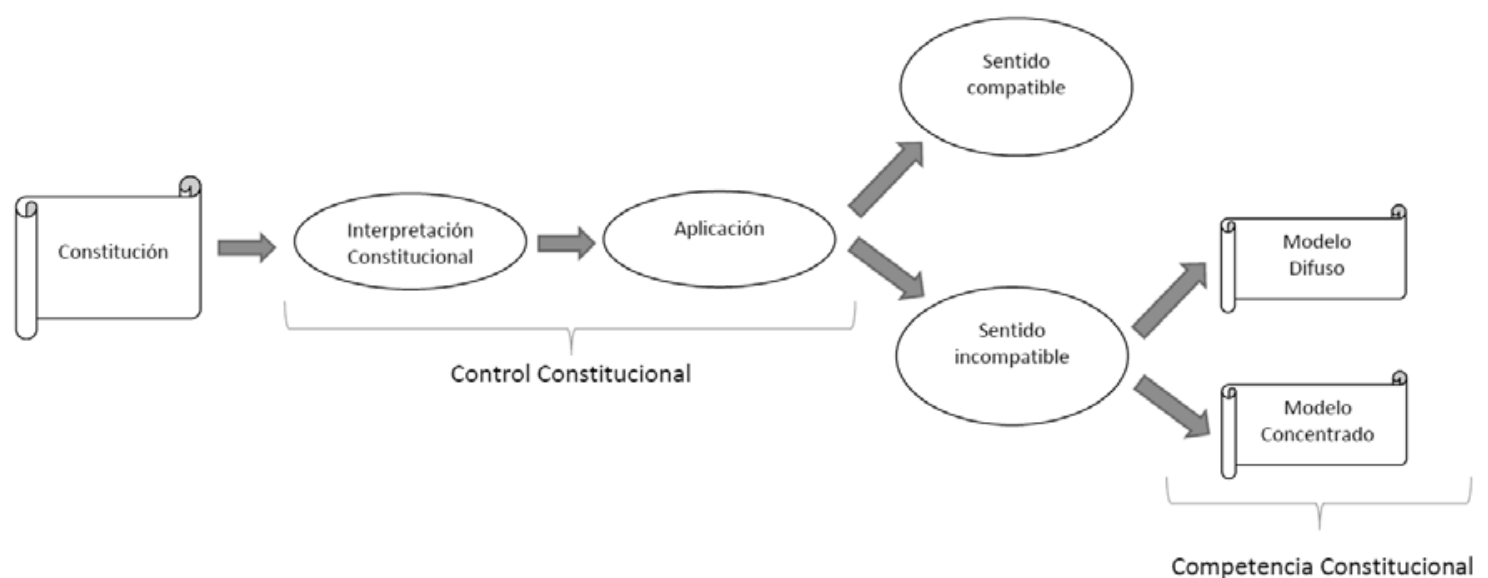

Véase en el gráfico que es la disposición constitucional el objeto de interpretación, claro está, suponiendo que aquella será materia de contraste con determinada disposición legal. A partir de dicho contraste se obtendrán diversos resultados interpretativos que pueden aplicarse en la realidad. Algunos tendrán sentidos «compatibles» con la Constitución y otros no. Ello supone, en consecuencia, que al realizar la labor de interpretación, el operador debe colocar sobre la mesa diversos sentidos interpretativos de los cuales escoge aquel que sea «conforme» con la Constitución. Así - como bien lo he tratado en alguna oportunidad con el profesor Renzo Cavani-, la labor del intérprete de explorar diversos sentidos interpretativos como consecuencia del contraste de la norma constitucional con la legal es lo lógico y adecuado. De allí que, indudablemente, si luego de practicar diversos sentidos interpretativos no existe ninguno que «salve» la disposición de la «incompatibilidad» constitucional — término que eligió el profesor Edward Dyer en una conversación sostenida sobre esta misma tesis - , ese sentido incompatible es el que conlleva a que el intérprete tome una decisión, siempre y cuando goce de competencia constitucional para hacerlo y que, además, esté en la vía orgánica adecuada para practicar tal competencia. Aquí es donde entran a tallar los modelos de control constitucional denominados difuso o concentrado.

Es necesario advertir que estos modelos han sido harto estudiados en la doctrina nacional y comparada, fundamentalmente, en lo que concierne a la declaración de inconstitucionalidad. Así, en el caso del modelo difuso, el efecto de considerar que una norma legal sea incompatible con la Constitución determina su inaplicación al caso concreto, mientras que, en el caso del concentrado, la consecuencia es la derogatoria de la disposición con efectos generales, expulsándola del ordenamiento jurídico.

No obstante, la operatividad que muestra el gráfico anterior ha sido un aspecto que no encuentro claramente plasmado en nuestra doctrina, menos aún en la jurisprudencia constitucional, pese a que existen planteamientos conceptuales que seguidamente voy a citar.

En efecto, considero que la carencia de claridad en esta operatividad funcional de la relación de interpretación-control constitucional es la que motiva el riesgo de confundir conceptos que he trabajado en las líneas precedentes y que, para evitar tal confusión, conllevan a considerar lo siguiente: la declaración de inconstitucionalidad importa, siempre, un ejercicio de interpretación constitucional y, por ende, de control de constitucionalidad. Por tanto, el objeto de control constitucional no son las disposiciones o enunciados jurídicos, sino las interpretaciones que el operador realice sobre aquellas, es decir, las normas que construya en torno a dichas disposiciones jurídicas ${ }^{16}$.

16 En lo sucesivo, emplearé el término norma cuando me refiera al resultado interpretativo de una determinada disposición o enunciado jurídico, es decir, una interpretación del texto legal. Estoy tomando como referencia la distinción hecha por Moreso (2014, pp. 157-158) que antes he citado (supra 4.1.). 
Así lo ha entendido la jurisprudencia del Tribunal Constitucional cuando se ha referido al criterio de interpretación de la ley conforme con la Constitución. En el fundamento $18^{\circ} \mathrm{de}$ la STC N. ${ }^{\circ}$ 01761-2008-PA/TC, el Supremo Intérprete de la Constitución señaló lo siguiente:

18०. Este criterio consiste en aquella actividad interpretativa que sobre las leyes realiza el Tribunal Constitucional, de modo que antes de optar por la eliminación de una disposición legal se procure mantenerla vigente pero con un contenido que se desprenda, sea consonante o guarde una relación de conformidad con la Constitución. Esta técnica interpretativa no implica en modo alguno afectar las competencias del legislador, sino antes bien materializar los principios de conservación de las normas y el in dubio pro legislatore democrático, los mismos que demandan que el Tribunal Constitucional verifique si entre las interpretaciones posibles de un enunciado legal, existe al menos una que la salve de una declaración de invalidez. Y es que la declaración de inconstitucionalidad, en efecto, es la última ratio a la cual debe apelar este tribunal cuando no sea posible extraer de una disposición legislativa un sentido interpretativo que se ajuste a la Constitución (Exp. No 00002-2008-PI/TC, aclaración).

Por ello, un ejercicio de interpretación constitucional importa, siempre, un acto de control constitucional, aunque no necesariamente su resultado conduce a una declaración de inconstitucionalidad. Es decir, en este último caso no siempre el control constitucional conducirá al ejercicio del control difuso o concentrado (dependiendo del modelo empleado), puesto que para ello se requiere dos cosas: desde el punto de vista instrumental, que no sea posible lograr un sentido interpretativo compatible con la Constitución, y, desde el punto de vista orgánico o funcional, que si el operador se encuentra frente a un sentido incompatible, debe contar con la competencia constitucional para aplicar el modelo difuso o concentrado, según sea el caso.

Eso explica por qué en el caso del control concentrado de constitucionalidad el $\mathrm{TC}$ ha desarrollado el contenido de las denominadas sentencias estimatorias y desestimatorias, puesto que cada uno de sus postulados toma como eje del control las interpretaciones de los enunciados o disposiciones jurídicas ${ }^{17}$.

17 Véanse los fundamentos $14 .^{\circ}$ a $17 .^{\circ}$ de la RTC N. $03133-$ 2011-PA/TC:

"14. A su vez, la sentencia de inconstitucionalidad, como especie del género sentencias de la jurisdicción constitucional orgánica, admite una ulterior clasificación atendiendo al tipo de fallo que aquella contiene, y esta es la siguiente (STC 0004-2004-CC/TC, fundamento 3 y ss.):

14.1. Sentencias estimatorias: que a su vez pueden ser de tres tipos:

14.1.1. Sentencias de simple anulación, en cuyo caso la declaración de inconstitucionalidad de la norma legal puede ser total o parcial.

14.1.2. Sentencias interpretativas propiamente dichas, modalidad en las que el Tribunal Constitucional declara la inconstitucionalidad de una interpretación errónea efectuada por algún operador juridico, quien a partir de entonces se encuentra prohibido de interpretar y aplicar aquella forma de interpretación declarada contraria a la Constitución.

14.1.3. Sentencias interpretativas-manipulativas, en las que el tribunal, verificando la existencia de un contenido normativo inconstitucional, procede a "reconstruir" dicho contenido para adecuarlo a la Constitución, para evitar efectos perniciosos. Presenta cuatro submodalidades:

14.1.3.1. Sentencias reductoras: cuya labor de 'reconstrucción' se limita a 'restringir' o ‘acortar' el contenido normativo de la norma legal impugnada.

14.1.3.2. Sentencias aditivas: en las que, luego de constatar una inconstitucionalidad por omisión legislativa, el tribunal 'añade' o 'integra' algo al texto normativo incompleto, para convertirlo en plenamente constitucional.

14.1.3.3. Sentencias sustitutivas: en ellas, el tribunal declara la inconstitucionalidad parcial de una ley y, a continuación, incorpora un contenido normativo en su reemplazo, que es siempre una norma ya vigente en el ordenamiento juridico.

1 4.1.3.4. Sentencias exhortativas: asi denominadas porque si bien declaran la inconstitucionalidad de la norma legal en cuestión, el tribunal no dispone su expulsión inmediata del ordenamiento jurídico, sino que concede al Congreso de la República un plazo para expedir la ley sustitutoria que sea conforme a la Constitución (vacatio sententiae). Por ello, debe distinguirse esta submodalidad de la sentencia exhortativa no vinculante, que supone una simple recomendación o sugerencia al legislador, pero sin declaración de inconstitucionalidad alguna.

14.2. Sentencias desestimatorias: dentro de las que cabe incluir dos submodalidades:

14.2.1. Sentencia desestimatoria por rechazo simple: que puede ser total o parcial.

14.2.2. Sentencia desestimatoria por sentido interpretativo: en las que la declaratoria de constitucionalidad de la norma legal en cuestión queda supeditada a que esta se interprete en el sentido fijado por el Tribunal Constitucional.

15. No obstante, como autorizada doctrina pone de manifiesto, para clasificar las sentencias recaidas en los procesos de inconstitucionalidad es posible acudir no solo a un criterio 'formal', es decir, atendiendo al fallo de la sentencia (pauta a la cual obedece la clasificación antes expuesta), sino también a un criterio 'material', que tenga en cuenta los efectos realmente producidos por el fallo sobre el contenido normativo del precepto cuestionado [Diaz Revorio, Francisco Javier: Las sentencias interpretativas del Tribunal Constitucional, Lex Nova, Madrid, 2001, pp. 64-64]. Y asi, a partir de esta comprensión, surgen tres importantes consecuencias: a) Toda sentencia que no es de desestimación pura, es de estimación parcial; b) todas las sentencias interpretativas son materialmente estimatorias, pues o bien entienden que al menos una de entre las varias interpretaciones posibles de un texto legal es contraria a la Constitución, o bien en un sentido más amplio que parte del contenido normativo es inconstitucional; y c) todas las sentencias formalmente interpretativas de desestimación, son materialmente interpretativas de estimación en sentido amplio (ibidem)". 


\section{¿CONTROL CONSTITUCIONAL DE ACTOS?}

Una cuestión que pareciera tautológica a estas alturas consiste en tener muy claro que el control constitucional no solo es normativo, sino también que opera sobre actos.

La jurisprudencia constitucional así lo ha puesto en relieve. En el fundamento $14^{\circ}$ de la STC N. ${ }^{\circ} 04053-2007-\mathrm{HC} / \mathrm{TC}$, el Tribunal Constitucional dijo:

14. . [...] Afirmar que existen actos de alguna entidad estatal cuya validez constitucional no puede ser objeto de control constitucional, supone sostener, con el mismo énfasis, que en tales ámbitos la Constitución ha perdido su condición de norma jurídica para volver a ser una mera carta política referencial, incapaz de vincular al poder (Cfr. Exp. $N^{o}$ 5854-2005-AA/TC). Es por ello que constituye una consecuencia directa del carácter jurídico de la Constitución, el control jurisdiccional de los actos de todos los poderes públicos y de los particulares.

Este criterio jurisprudencial es lo que el propio TC conoce como la inexistencia de zonas exentas del control constitucional. Así, existe una cobertura de control vertical (actos estatales) y horizontal (actos inter privatos) que, al tratarse de situaciones concretas, gira en torno al análisis de compatibilidad de tales actos con el ejercicio u observancia de los derechos fundamentales, lo cual supone el empleo de los denominados procesos constitucionales de la libertad (habeas corpus o amparo, según sea el derecho que se busque tutelar) $\mathrm{u}$ ordinarios, puesto que, como ya lo he dicho en otra oportunidad (López Flores, 2017 , p. 15), no debe confundirse proceso constitucional con caso constitucional. Esto último atañe a aquella situación fáctica en la que acontece la necesidad de proteger los derechos fundamentales ante una violación o amenaza de violación de tales derechos, independientemente de la vía procesal empleada por la víctima para tutelarlos. Por tanto, los casos constitucionales no son patrimonio exclusivo de los denominados procesos constitucionales.

\section{¿QUIÉNES TIENEN LEGITIMIDAD PARA EJERCER EL CONTROL CONSTITUCIONAL?}

Las Constituciones de 1979 y 1993 establecieron en el Perú un sistema de control constitucional jurisdiccional. Y ya se ha visto anteriormente (supra 4) que el control supone el ejercicio de interpretación constitucional por el cual se determina si una norma que se desprende de la disposición legal o infralegal resulta ser compatible o incompatible con la norma constitucional. En ese sentido, si se determina la incompatibilidad, solo pueden tomar acción al respecto aquellos órganos constitucionales que cuenten con facultades para determinar si aplican el modelo difuso o el concentrado según el modelo de control que ejerzan. Es decir, los únicos que pueden ejercer esas competencias son los órganos jurisdiccionales designados por la Constitución para tal propósito.

En un trabajo anterior (López Flores, 2016, pp. 156-158) he dicho que la jurisprudencia del Tribunal Constitucional ha construido la tesis del "sistema jurisdiccional unitario") (fundamento $10{ }^{\circ}$ de la STC N. ${ }^{\circ}$ 0004-2006-PI/TC), es decir, que cuando la Constitución dice que el llamado a ejercer la función jurisdiccional es el Poder Judicial, eso no quiere decir que sea el único con ese poder, sino que dicho sistema está compuesto por otras entidades que también lo ostentan: el Tribunal Constitucional, el JNE, la justicia militar, la justicia arbitral, la justicia comunal (STC N. ${ }^{\circ} 6167-$ 2005-PHC/TC, fundamento $7 .^{\circ}$, caso Fernando Cantuarias Salaverry), el juicio político contra los altos funcionarios de la jerarquía estatal (artículos 99. ${ }^{\circ}$ y $100{ }^{\circ}$ de la Constitución), la función sancionatoria-disciplinaria del Consejo Nacional de la Magistratura (artículo 154.3 de la Constitución) que tiene inmutabilidad y que ha sido interpretada constitucionalmente por el TC en la STC $N{ }^{\circ}$ 05156-2006-PA/TC (caso Vicente Walde Jáuregui), en el sentido en que requiere la observancia estricta de las garantías del debido proceso.

Asi las cosas, desde la perspectiva funcional, el poder de resolver conflictos (función jurisdiccional) es único y 
exclusivo del Estado, cuya génesis se encuentra en el principio de soberanía popular (el poder emana del pueblo); sin embargo, desde una perspectiva orgánica, ese poder se ejerce de modo dividido en determinados órganos o autoridades a quienes la Constitución les ha autorizado a ejercerla. Y tal autorización surge de manera explícita o implícita a la luz del marco constitucional ${ }^{18}$. No podría ser de otro modo; así se resguarda la exclusividad de la función.

De esta manera, si bien funcionalmente el poder jurisdiccional es uno solo, orgánicamente lo ejercen diversos órganos $o$ autoridades. Todos ellos en conjunto conforman un sistema jurisdiccional unitario, al que -en mi concepto - con propiedad se ha referido el Tribunal Constitucional en su jurisprudencia. Y desde esa perspectiva surge una relectura del primer párrafo del artículo $138^{\circ}$ de la Constitución: La potestad de administrar justicia emana del pueblo y se ejerce por los órganos y autoridades investidos del poder jurisdiccional (jurisdicción) a través de sus órganos jerárquicos con arreglo a la Constitución y a las leyes. Hay, pues, desde el punto de vista estamental y funcional, varios "Poderes Judiciales» en el Perú.

Ahora bien, como quiera la Constitución, el $\mathrm{TC}$ es el único con competencia para ejercer el control concentrado en los procesos de inconstitucionalidad de normas con rango de ley; por defecto, el control difuso de constitucionalidad podrán ejercerlo todos los demás órganos investidos de la función jurisdiccional, tal como lo ha dicho el TC en el fundamento $2^{\circ}$ de la STC $N^{\circ} 1680-2005-P A /$ TC, caso Jorge Luis Borja Urbano [subrayados agregados]:

2. Este tribunal tiene dicho que el control judicial de constitucionalidad de las leyes

18 Así, explícitamente, la Constitución les reconoce poder jurisdiccional al Poder Judicial (artículo $138^{\circ}$ ), a los fueros militar y arbitral (artículo 139.1 ${ }^{\circ}$ ), a las comunidades campesinas y nativas (artículo $149^{\circ}$ ) y al Jurado Nacional de Elecciones (artículos $178.1^{\circ}$ y $181^{\circ}$ ). Implícitamente, en vista que declaran derecho, sus decisiones son inmutables, pueden ejecutar el cumplimiento de tales decisiones (coertio) y le son aplicables las garantías del debido proceso; puede decirse que el CNM ejerce función jurisdiccional en materia de destitución de magistrados supremos (artículo 154.3), así como sucede lo propio con el Congreso de la República en materia de juicio político (artículos $99^{\circ}$ y $100^{\circ}$ ) es una competencia reconocida a todos los órganos jurisdiccionales para declarar la inaplicabilidad constitucional de la ley, con efectos particulares, en todos aquellos casos en los que la ley aplicable para resolver una controversia, resulta manifiestamente incompatible con la Constitución (control difuso).

Como tal, se trata de un poder-deber del juez, consustancial a la Constitución del Estado constitucional, la cual, por lo demás, tiene como características la de ser una auténtica norma jurídica, constituir la Ley Fundamental de la Sociedad y del Estado, constituyendo así un derecho directamente aplicable. $Y$ es que como sostuviera el Chief Justice Jhon Marshall al redactar la opinión de la Corte Suprema en el Leanding Case Marbury v. Madison, resuelto en 1803.

\section{LOS ESPACIOS DE ACCIÓN DEL CONTROL DIFUSO}

Desde el punto de vista operativo, veamos ahora cómo se desarrolla el control difuso de constitucionalidad en el Perú. En mi concepto existen dos ámbitos: en sede de la justicia ordinaria y en sede de la justicia constitucional.

\section{La justicia ordinaria}

Como ya se ha visto, el control difuso es una potestad que va atada al ejercicio de la función jurisdiccional. En el Perú, esta puede ser ejercida por cualquiera de los órganos autorizados por la Constitución y a los que ya me he referido anteriormente (supra 6).

Cuando el Tribunal Constitucional publicó el precedente vinculante Elgo Ríos Núñez, comenté el fallo señalando que este presentaba tanto una importancia práctica - por las reglas procesales establecidas, esencialmente, en su fundamento $15^{\circ}$ - como una gran importancia política, puesto que más allá de la pertinencia - o no- de las reglas implantadas por el TC en dicho precedente, aquellas impactan en el rol de la judicatura ordinaria (López Flores, 2015, p. 32).

Considero que ese impacto en el rol de la judicatura ordinaria resulta medular para el operador práctico: en la medida en que los procesos constitucionales de la libertad 
(como el amparo y el habeas corpus) han sido diseñados por el legislador del CPC como el último remedio contra la agresión de derechos fundamentales, tal opción legislativa coloca el peso de la protección de tales derechos, en primer y esencial lugar, sobre los hombros de los jueces ordinarios; $y$, en segundo y extraordinario lugar, en los de los jueces que conocen los procesos constitucionales de la libertad. Por tanto, los «casos constitucionales» no son patrimonio exclusivo de los procesos constitucionales $\mathrm{y}$, por lógica consecuencia, los jueces ordinarios que conocen procesos de cualquier especialidad representan lo que denomino justicia constitucional difuminada.

Se trata, pues, de un cambio de concepción estratégica del «caso constitucional» que el operador tenga en sus manos, puesto que debe pensar, primero que nada, que en el proceso ordinario debe encontrar tutela a los derechos constitucionales agredidos o amenazados. Si el asunto es urgente y la vía ordinaria o el agotamiento de las vías previas no es satisfactorio, entonces la recurrencia al amparo constituye el movimiento táctico a elegir.

Me explico.Laresidualidad es una característica propia y originaria del amparo en la Argentina, cuya flexibilización - como así reporta Sagüés (2009, pp. 35-36) - es materia de debate, además de los severos cuestionamientos de un sector doctrinal sobre la estructura del modelo vigente (Rojas, 2004, pp. 430-434) y de la formulación de interesantes propuestas para su reforma (Berizonce, 2010, p. 429).

Pues bien, el precedente Elgo Ríos es el corolario de una tendencia jurisprudencial dictada por el TC - desde que entró en vigencia el $\mathrm{CPC}$ - que reafirma y consolida el modelo de residualidad de los procesos constitucionales de la libertad. Así, cuando en este precedente el TC establece cuatro reglas para determinar cuándo la vía ordinaria será «igualmente satisfactoria» a la constitucional de la libertad (fundamento $\left.15^{\circ}\right)^{19}$, apréciese que todas ellas afirman, en sustancia, que el primer peldaño de la protección constitucional de los derechos fundamentales está en manos de la judicatura ordinaria en cualquier caso

19 Estas reglas son: a) que la estructura del proceso es idónea para la tutela del derecho; b) que la resolución que se fuera a emitir podría brindar tutela adecuada; $c$ ) que no existe riesgo de que se produzca la irreparabilidad; y d) que no existe necesidad de una tutela urgente derivada de la relevancia del derecho o de la gravedad de las consecuencias. civil, comercial, penal, laboral, etc. Lo digo porque no creo que estemos ante simples «vías paralelas» o «igualmente satisfactorias», como la jurisprudencia y la doctrina nacional arguyen, sino que a partir de la residualidad se habría instituido, formalmente, un modelo que denomino justicia constitucional difuminada $\mathrm{y}$, con ello, la regla general de que, ante los jueces ordinarios, los ciudadanos peruanos tenemos el deber de recurrir a ellos a través de los procesos judiciales activados para dilucidar el conflicto intersubjetivo derivado de nuestras relaciones jurídicas (civiles, familiares, comerciales, etc.), para solicitar la tutela de nuestros derechos fundamentales.

En otras palabras, la regla excepcional de recurrencia al amparo por su carácter residual habría impulsado la regla general de que los procesos judiciales ordinarios son auténticos «amparos ordinarios», término que acuño, dado que es allí donde el juez podrá realizar el control constitucional tanto de normas como de actos (estatales o inter privatos) que amenacen o vulneren derechos fundamentales. Por eso es que también acuño el término de justicia constitucional difuminada debido a que el «caso constitucional» puede acontecer en cualquier tipo de proceso o especialidad. El carácter transversal de los derechos fundamentales toma, pues, especial relevancia y protagonismo porque el pedido de su tutela debe ser materia expresa de las pretensiones de la demanda o al momento de ejercer la defensa. Este parecer no es ajeno a la jurisprudencia del TC, puesto que en el fundamento $12^{\circ}$ de la RTC N. ${ }^{\circ}$ 3694-2012-PA/TC (caso Mario Torres Andrade), el Supremo Intérprete de la Constitución dijo:

En lajurisdicción constitucional comparada es pacifico asumir que el primer nivel de protección de los derechos fundamentales les corresponde a los jueces del Poder Judicial a través de los procesos judiciales ordinarios. Conforme al artículo $138^{\circ}$ de la Constitución, los jueces administran justicia con arreglo a la Constitución y las leyes, puesto que ellos también garantizan una adecuada protección de los derechos y libertades reconocidos por la Constitución. Sostener lo contrario significaría afirmar que el amparo es el único medio para salvaguardar los derechos constitucionales, a pesar de que a través de otros procesos judiciales también es posible obtener el 
mismo resultado. De igual modo, debe tenerse presente que todos los jueces se encuentran vinculados por la Constitución y los tratados internacionales de derechos humanos; más aún, la Constitución los habilita a efectuar el control difuso conforme a su artículo 138 . (Cfr. Exp. $N^{o}$ 3792-2010-AA/TC)

Por ello es que esta premisa resulta medular, dado que presiona por un "cambio de enfoque» o de «concepción estratégica» tanto de los litigantes como de los jueces ordinarios en torno al rol de estos últimos en los casos que conocen. Solo a partir de esta «nueva visión» es que cobra especial y relevante sentido aquello que señala Rodríguez Santander (2005):

El art. $5^{\circ} 2$ CPConst constituye un verdadero desafio tanto para la jurisdicción constitucional como para la jurisdicción ordinaria. Por un lado, se ha confiado al criterio del juez constitucional la identificación de aquellos casos de relevancia constitucional que merecen una pronta dilucidación, a efectos de evitar la irreparable incidencia sobre el contenido constitucionalmente protegido de los derechos reconocidos por la Norma Fundamental. [...], (p. 98)

Por otra parte, se ha reservado a la jurisdicción ordinaria la debida tutela de los derechos fundamentales en el resto de casos. Ello exige que el juez ordinario comprenda, hoy más que nunca, que la adecuada y eficiente protección de los derechos fundamentales no son funciones exclusivas de algún órgano ad hoc, sino que a él, en tanto miembro del Poder Jurisdiccional, competen también, en igual intensidad, dichas tareas. Para tales efectos, será deber de todos los jueces capacitarse para una pertinente valoración del contenido protegido por los derechos fundamentales, pues solo así se encontrarán en condiciones de determinar cuándo corresponde declarar la inconstitucionalidad de algún acto. De otra parte, es deber del Estado adoptar medidas legislativas y logísticas que permitan potenciar a la jurisdicción ordinaria en la defensa de los derechos fundamentales, sin perjuicio de implementar, cuanto antes, los juzgados especializados encargados de conocer los amparos en primera y segunda instancia, a los que hace alusión la Tercera Disposición Final CPConst.

Claro está, vuelvo a insistir, este «involucramiento» no solo es de los jueces sino, esencialmente, de los litigantes, quienes son los que ponen en el tablero de juego de la justicia constitucional amparos que pudieron plantearse en la justicia constitucional ordinaria o difuminada. Esta tesis consolida la idea de que, por el modelo de la residualidad, el primer nivel de tutela jurisdiccional está en manos de la judicatura ordinaria, lo cual torna absolutamente excepcional a los procesos constitucionales de la libertad. Allí tiene sentido que constituyan «el último remedio contra la agresión». Por tanto, la «constitucionalización» de los casos debe estar en manos de los jueces que conocen los procesos ordinarios, más aún si sumamos la variedad de medidas cautelares que estos contemplan y que sirven para tutelar las situaciones de urgencia y vulnerabilidad de los derechos fundamentales que constituyen el núcleo del caso.

En esta tarea de «detectar» los procesos judiciales ordinarios que sirvan para tutelar los derechos fundamentales (como primer nivel de tutela), considero que existen: i) las vías legales (y jurisprudenciales) específicas; ii) la renuncia a recurrir al amparo para acudir a la vía ordinaria con similar pretensión, pero con un mayor debate probatorio; y iii) el enfoque constitucional de los procesos judiciales ordinarios ${ }^{20}$. Así las cosas, es la justicia ordinaria -independientemente de los procedimientos y jueces competentes - la llamada a ejercer el control constitucional difuso. Pero ¿cómo y cuándo ejercen tal potestad? En mi concepto, existen dos supuestos que los he clasificado o dividido en lo que denomino la cuestión incidental y el control vía acción.

$20 \mathrm{Y}$ en cuanto al enfoque constitucional de los procesos judiciales ordinarios, entiendo que aquí es donde la regla general impulsada, a su vez, por la regla excepcional que implica la residualidad (es decir, que el primer nivel de tutela de los derechos fundamentales le corresponde al juzgador ordinario) se muestra en toda su dimensión. Significa que el recurrente, por ejemplo, cuando demanda ante un juez civil la indemnización por daños y perjuicios causados por un medio de prensa que vulneró su privacidad, deberá tener especial cuidado en advertir que su caso no es exclusivamente de indole civil, porque el daño es uno de relevancia constitucional en vista de que si bien incide en la esfera de su derecho fundamental a la privacidad, puede que no sea tutelado si es que, por el contrario, se tutela el ejercicio a la libertad de expresión e información del medio de prensa demandado si se comprueba que este actuó en defensa del interés público de la información privada divulgada. 


\section{La cuestión incidental}

Desde mi punto de vista, el control difuso en sede ordinaria puede surgir incidentalmente en cualquier tipo de proceso o especialidad. Así lo deduzco de lo que señala el artículo $14^{\circ}$ del TUO de la Ley Orgánica del Poder Judicial ${ }^{21}$, que hace bloque de constitucionalidad con lo dispuesto por el artículo $138 .^{\circ}$ de la Constitución.

Nótese que el primer párrafo del texto legal citado se coloca en la hipótesis de que el juez, al momento de sentenciar, advierte la «cuestión de inconstitucionalidad» de alguna norma aplicable al caso concreto que está juzgando. Esto podría darse bien de oficio o bien ha pedido de parte y en cualquiera de las etapas previas del proceso. Por ejemplo, podría haber sido introducida por el demandado en un proceso civil al momento de contestar la demanda, podría haber sido deducida por el fiscal en un proceso penal en la instrucción o el juzgamiento, $\mathrm{O}$ simplemente es el juez quien advierte el problema motu proprio. Lo cierto es que la ley establece que la decisión que tome al respecto deberá plasmarse en la sentencia.

A diferencia de la experiencia española de la denominada «cuestión de inconstitucionalidad» (Pérez Tremps, 2006, pp. 775 y ss.), apréciese que el proceso no se suspende, sino que se le faculta al juez a que tome la decisión en un fallo que, de no ser impugnado, será elevado en consulta teniendo como último supervisor a la Sala Constitucional y Social de la Corte Suprema. Evidentemente, aquí se identifica una falla en el diseño del modelo, puesto que el TC debiera canalizar este incidente debido a su rol de Supremo Intérprete de la Constitución (artículo $1^{\circ}$ de su Ley Orgánica, Ley N. ${ }^{\circ} 28301$ ).

\footnotetext{
21 TUO de la Ley Orgánica del Poder Judicial

"Artículo $\mathbf{1 4}^{\circ}$. De conformidad con el Art. 236 de la Constitución, cuando los magistrados al momento de fallar el fondo de la cuestión de su competencia, en cualquier clase de proceso o especialidad, encuentren que hay incompatibilidad en su interpretación, de una disposición constitucional y una con rango de ley, resuelven la causa con arreglo a la primera. Las sentencias así expedidas son elevadas en consulta a la Sala Constitucional y Social de la Corte Suprema, si no fueran impugnadas. Lo son igualmente las sentencias en segunda instancia en las que se aplique este mismo precepto, aun cuando contra estas no quepa recurso de casación.

En todos estos casos, los magistrados se limitan a declarar la inaplicación de la norma legal por incompatibilidad constitucional, para el caso concreto, sin afectar su vigencia, la que es controlada en la forma y modo que la Constitución establece.

Cuando se trata de normas de inferior jerarquía, rige el mismo principio, no requiriéndose la elevación en consulta, sin perjuicio del proceso por acción popular".
}

\section{¿Puede plantearse vía acción?}

Sostengo que la discusión sobre la constitucionalidad de normas legales puede plantearse vía acción en sede de la justicia ordinaria. Tal discusión puede articularse bien contra normas producidas por el Estado o por los particulares, puesto que la jurisprudencia constitucional peruana admite que la vulneración de derechos fundamentales puede darse desde el Estado (vulneración «vertical») como entre privados («vulneración horizontal»). De allí que el Tribunal Constitucional haya admitido en la STC N. ${ }^{\circ}$ 03843-2003-AA/TC que:

4. (...) en virtud del artículo $138^{\circ}$ de la Constitución y del artículo $3^{\circ}$ del CPConst., la facultad de controlar la constitucionalidad de las normas autoaplicativas constituye un poder-deber para el juez; por ello, las normas privadas que sean contrarias a los derechos constitucionales han de ser inaplicadas en cada caso concreto, esto al margen del control abstracto de las normas legales en la vía que corresponda.

En mi concepto, el proceso contenciosoadministrativo (proceso ordinario por naturaleza) prevé la posibilidad de que el cuestionamiento a un acto de la administración implique el control constitucional de una norma legal en el inciso $1 .^{\circ}$ del artículo $9 .^{\circ}$ de la Ley del Proceso Contencioso Administrativo ${ }^{22}$, en otras palabras, el control vía acción. Claro está que ese tipo de control es indirecto contra normas, porque la pretensión de invalidación del acto administrativo es la puerta de entrada para cuestionar la norma tildada de «inconstitucional»y que el primero habría aplicado al caso concreto.

Lo propio podría realizarse en aquellos casos en los que, por cuestiones tácticas, el operador práctico decide renunciar a recurrir al amparo para acudir a la vía ordinaria con similar pretensión, pero con un mayor

\footnotetext{
22 Ley del Proceso Contencioso Administrativo (TUO, D.S. N. ${ }^{\circ} 013-$ 2008-JUS)

"Articulo $9^{\circ}$. Facultades del Órgano Jurisdiccional

Son facultades del órgano jurisdiccional las siguientes: 1. Control Difuso

En aplicación de lo dispuesto en los artículos 51 y 138 de la Constitución Política del Perú, el proceso contencioso administrativo procede aun en caso de que la actuación impugnada se base en la aplicación de una norma que transgreda el ordenamiento jurídico. En este supuesto, la inaplicación de la norma se apreciará en el mismo proceso".
} 
debate probatorio. Me refiero a que el acceso excepcional, residual a la vía del amparo constituye - en mi opinión - una carga de la prueba del recurrente. En efecto, dado que la regla general es el conocimiento de estos tópicos por la vía judicial ordinaria, ¿podría el recurrente, aun cuando esté en capacidad de probar la excepcionalidad de acceder al amparo, renunciar a dicha vía y conducir sus pretensiones a la vía ordinaria? Dado que los jueces ordinarios son el primer nivel de protección, no veo por qué no pueda hacerlo. Me coloco en la hipótesis de lo que denomino amparo ordinario contra normas autoaplicativas, es decir, aquella demanda planteada por una persona con el propósito de que no se apliquen, a su caso concreto, los efectos de una norma autoaplicativa por considerarla infractora de sus derechos fundamentales. Por el carácter autoaplicativo de la disposición, el recurrente puede recurrir a la vía excepcional del amparo (artículo $3^{\circ}$ del Código Procesal Constitucional); sin embargo, supongamos que decide renunciar a dicha vía porque la vulneración de sus derechos puede acreditarla a través de un mayor debate probatorio. Podría ser que interpone la demanda contra una norma tributaria, puesto que considera que su aplicación concreta importaría la confiscatoriedad de su patrimonio - lo cual contraría el principio constitucional de «no confiscatoriedad» previsto en el artículo $74^{\circ}$ de la Constitución-. Y para probar tal confiscatoriedad, requiere de un mayor debate probatorio que el amparo no soporta, pero el proceso ordinario sí. Por ejemplo, una pericia contable y financiera que demuestre que, si dicha norma le fuera aplicable, sería infractora del principio constitucional de no confiscatoriedad de los tributos ${ }^{23}$.

\footnotetext{
23 Asi lo señala el Tribunal Constitucional en el fundamento 38. de la STC $\mathrm{N}^{\circ}$ 06089-2006-PA/TC, donde expresamente dijo lo siguiente:

"38. Por lo tanto, resulta gratuito apelar al principio de no confiscatoriedad cuando no se aportan pruebas suficientes para su comprobación. Respecto al principio de no confiscatoriedad en materia tributaria, este colegiado ha advertido en reiterada jurisprudencia lo siguiente:

[...] se transgrede el principio de no confiscatoriedad de los tributos cada vez que un tributo excede el limite que razonablemente puede admitirse como justificado en un régimen en el que se ha garantizado constitucionalmente el derecho subjetivo a la propiedad y, además, ha considerado a esta como institución, como uno de los componentes básicos y esenciales de nuestro modelo de constitución económica" (STC N. ${ }^{\circ}$ 2727-2002-AA/TC).

$\mathrm{Su}$ contenido constitucionalmente protegido no puede ser precisado en términos generales y abstractos, sino que debe ser analizado y observado en cada caso, teniendo en consideración la clase de tributo y las circunstancias concretas de quienes estén obligados a sufragarlo. No
}

\section{La justicia constitucional: el caso del amparo contra normas}

La doctrina norteamericana, influyente en el proceso histórico y social de Latinoamérica en materia de la protección procesal de los derechos fundamentales, originó la adopción de diversos instrumentos adaptados a la realidad de cada uno de nuestros pueblos y a nuestros sistemas jurídicos dirigidos a esta tarea.

En el caso del proceso de amparo, podemos apreciar que los antecedentes históricos de su institucionalidad en Latinoamérica se encuentran, de manera relevante, tanto en México como en Argentina, destacando el primero por instituir este mecanismo a nivel positivo por primera vez en la región y el mundo - constituyendo el gran aporte de Latinoamérica al derecho procesal constitucional mundial-; $\mathrm{y}$, en cuanto al segundo, por hacer lo propio a nivel jurisprudencial.

En México, a pesar de que existía ya una tendencia jurídica para crear un medio protector del régimen constitucional, aquel no adopta aún la forma clara y sistemática con que se le revistió en la Constitución del Estado de Yucatán de 1840, cuyo único autor fue el jurista y político Manuel Crescencio Rejón (Burgoa, 1979, p. 115), y que sirvió de referencia para su consagración por Mariano Otero en el documento titulado Acta de Reformas dirigido a la Constitución Federal de 1824, expedido en 1847 , así como por los constituyentes de 18561857 (Fix-Zamudio, 1988, p. 16).

Por su parte, en Argentina el amparo surge primero en la jurisprudencia de la Corte

obstante, teniendo en cuenta las funciones que cumple en nuestro Estado democrático de derecho, es posible afirmar, con carácter general, que se transgrede el principio de no confiscatoriedad de los tributos cada vez que un tributo excede el limite que razonablemente se admite para no vulnerar el derecho a la propiedad.

En los casos [en] que se alegue confiscatoriedad, es necesario que la misma se encuentre plena y fehacientemente demostrada. De lo contrario, corresponderá atender este tipo de procesos en otra via, donde sí puedan actuarse otros medios de prueba y proceda la intervención de peritos independientes que certifiquen las afectaciones patrimoniales a causa de impuestos (STC 2302-2003-AA/TC).

Existe dificultad en la demostración de confiscatoriedad en el caso de los impuestos indirectos, como el selectivo al consumo; de ahi la necesidad de mayores pruebas en estos supuestos para demostrar, por ejemplo, que el impuesto no fue trasladado, es decir, que el recurrente asumió - sin derecho a crédito fiscal- la carga del mismo, y, además, siendo asi, le trajo perjuicios a la economía de la empresa (STC 2302-2003-AA/TC)". 
Suprema Federal a través de los casos Ángel Siri (contra actos de autoridad pública) y Samuel Kot (contra actos de particulares), expedidos en 1957 y 1958, respectivamente, y cuyo desarrollo enraizó, a ese nivel, esta vía procesal en su sistema jurídico, hasta que fue dictada la Ley Nacional sobre Acción de Amparo (Ley N. ${ }^{\circ} 16986$ ) el 18 de octubre de 1966 con ciertas restricciones, y luego instituido también a nivel positivo a través del artículo $321 .^{\circ}$ del Código Procesal Civil y Comercial de la Nación el 20 de setiembre de 1967 (ibidem, pp. 29-30).

En el caso argentino, la importancia del desarrollo jurisprudencial de mecanismos de protección procesal tan relevantes, como el proceso de amparo, han llevado a afirmar a cierto y respetable sector de la doctrina de ese país (Bianchi, 1990, p. 116) que, si bien es cierto que sus tribunales de justicia no están compelidos a fallar conforme al precedente al igual que los británicos, los norteamericanos y todos los seguidores del sistema anglosajón del stare decisis-, ello no les resta la posibilidad creadora que se les asigna. Ha sido ella la que ha permitido la creación de instituciones tan arraigadas como el amparo, o bien las modalidades que conforman el ámbito excepcional del recurso extraordinario para recurrir ante la Suprema Corte Federal Argentina, es decir, la sentencia arbitraria y la gravedad institucional.

En el Perú, la Constitución de 1993 ratifica la institucionalidad del proceso de amparo constitucional al establecer, en el inciso $2^{\circ}$ del artículo $200^{\circ}$, que procede "contra el hecho u omisión, por parte de cualquier autoridad, funcionario o persona, que vulnera o amenaza los demás derechos reconocidos por la Constitución [...]. No procede contra normas legales ni contra resoluciones judiciales emanadas de procedimiento regular»; sin embargo, la prohibición constitucional de promover procesos de amparo contra normas legales ha sido interpretada de manera coherente y pacífica por la jurisprudencia de nuestro Tribunal Constitucional en el sentido en que no procede contra normas de carácter heteroaplicativo, mas solamente contra aquellas autoaplicativas ${ }^{24}$.

24 Por todas, véase el fundamento $4^{\circ}$ de la STC N. ${ }^{\circ}$ 1405-2010$\mathrm{PA} / \mathrm{TC}$ donde el Supremo Intérprete de la Constitución dijo: "4. En el presente caso, resulta pertinente que este tribunal exponga lo que en reiterada y constante jurisprudencia se
De esta manera, el amparo peruano se adherido al modelo mexicano de amparo contra normas directo, siempre que se trate de normas autoaplicativas. No obstante, la jurisprudencia del Tribunal Constitucional también ha recogido el modelo argentino de amparo indirecto contra normas, al establecer las pautas para aplicar el control constitucional difuso en la STC N. ${ }^{\circ} 01680-2005-A A / \mathrm{TC}^{25}$.

De lo dicho por el Supremo Contralor Constitucional, es claro que el cuestionamiento directo contra una norma podrá darse siempre en el hipotético caso en que esta pueda causar agravio al momento en que sea aplicada al caso concreto (agravio hipotético). En este caso, para los efectos de no caer en el control abstracto, se requiere que la norma tenga carácter autoaplicativo. Sin embargo, apréciese que lo dicho por la jurisprudencia también alude al control indirecto contra normas, siempre que hayan sido aplicadas al caso concreto y cause un agravio al actor. Así, se combate el acto concreto que resulta de la aplicación de la norma tildada de inconstitucional, de tal manera que controlando la constitucionalidad del acto se permite el control de la norma. De esta forma, queda acreditado que nuestro

ha establecido sobre el amparo contra normas. Así, si bien en principio no es procedente el amparo contra normas heteroaplicativas, si procede contra normas autoaplicativas, es decir, contra aquellas normas creadoras de situaciones juridicas inmediatas, sin la necesidad de actos concretos de aplicación. En efecto, del fundamento 10 de la STC 032832003-AA/TC se infiere que cuando las normas dispongan restricciones y sanciones sobre aquellos administrados que incumplan en abstracto sus disposiciones, queda claro que por sus alcances se trata de una norma de carácter autoaplicativo, que desde su entrada en vigencia generará una serie de efectos jurídicos que pueden amenazar o violar derechos fundamentales". Cfr. http://www.tc.gob.pe/ jurisprudencia/2011/01405-2010-AA.html

25 En este fallo ha dicho el Tribunal Constitucional:

"6. B) En segundo lugar, el control de constitucionalidad solo podrá practicarse siempre que la ley de cuya validez se duda sea relevante para resolver la controversia sometida al juez. En ese sentido, el juez solo estará en actitud de declarar su invalidez cuando la ley se encuentra directamente relacionada con la solución del caso, término este último que no puede entenderse como circunscrito solo a la pretensión principal, sino que comprende, incluso, a las pretensiones accesorias que se promuevan en la demanda o se establezcan en la ley.

El juicio de relevancia que subyace al ejercicio válido del control de constitucionalidad no solo tiene el propósito de recordar el carácter jurídico del control de constitucionalidad de las leyes, sino también de erigirse como un limite a su ejercicio mismo, puesto que, como antes se ha recordado, en los procesos de la libertad está vedado cuestionar hipotética o abstractamente la validez constitucional de las leyes (nemo iúdex sine actor).

7. C) En tercer lugar, y directamente relacionado con el requisito anterior, es preciso que quien plantee al juez la realización del control judicial de constitucionalidad de la ley acredite que su aplicación le ha causado o pueda causarle un agravio directo, pues, de otro modo, el juez estaria resolviendo un caso abstracto, hipótetico o ficticio". [subrayado agregado] 
sistema de control constitucional difuso también opera en el marco de la justicia constitucional propiamente dicha.

\section{EL FUNCIONAMIENTO DEL CONTROL CONCENTRADO Y EL ROL DEL TRIBUNAL CONSTITUCIONAL}

En lo que concierne al control concentrado, el inciso $4^{\circ}$ del artículo $200^{\circ}$ de la Constitución ha previsto la acción de inconstitucionalidad, cuyo efecto es el de derogar la disposición legal cuestionada, tal como lo dispone el artículo $204 .^{\circ}$ de la misma Ley Fundamental. Y tal como dispone el inciso $1^{\circ} \mathrm{del}$ artículo $202^{\circ}$ de la Constitución, el proceso se tramita en única instancia ante el Tribunal Constitucional. Mención particular merece el proceso de acción popular que se encuentra previsto en el inciso $5^{\circ}$ del artículo $200^{\circ}$ de la Carta de 1993; y es que «procede, por infracción de la Constitución y de la ley, contra los reglamentos, normas administrativas y resoluciones y decretos de carácter general, cualquiera sea la autoridad de la que emanen».

Nótese que la diferencia con el proceso de inconstitucionalidad consiste en que este procede contra normas con rango de ley o tratados, mientras que la acción popular procede contra normas generales de rango inferior a la ley. No obstante, a diferencia también de los procesos constitucionales de la libertad (amparo, habeas corpus, cumplimiento, habeas data), este no versa sobre un cuestionamiento a un acto u omisión, sino que se dirige a cuestionar, en abstracto, una norma infralegal.

En este sentido, podemos decir con propiedad que el control concentrado de constitucionalidad está representado tanto en el proceso de inconstitucionalidad como en el proceso de acción popular. Sin embargo, el Constituyente olvidó otorgarle competencia al Tribunal Constitucional para que emita pronunciamiento definitivo en este último proceso constitucional. Ello ha originado que las normas de desarrollo (Código Procesal Constitucional) contemplen que la revisión final está en manos de la Corte Suprema, lo cual contradice el rol contralor de la constitucionalidad que le confiere al Tribunal Constitucional el artículo $201^{\circ}$ de la Constitución.
En relación con el primer párrafo del artículo $201^{\circ}$ de la Constitución vigente, este señala que el TC «es el órgano de control de la Constitución»; no dice que es «Supremo Intérprete». Es la vigente LOTC la que en el artículo $1^{\circ}$ así lo dispone. No se trata de un asunto de mera nomenclatura, porque la necesidad de enfatizar el rol de «Supremo Intérprete» que tiene el TC encuentra sentido en una política de evitar colisiones de criterios entre los jueces del Poder Judicial y dicho órgano constitucional, dado que ambos tienen el poder de control difuso de constitucionalidad. Ello importa que un modelo de control constitucional compartido o dual entre quienes ejercen función jurisdiccional por autorización y mandato de la Constitución requiera de un órgano rector que los supraordine.

El artículo $1^{\circ}$ de la LOTC señala que ese papel lo tiene el TC. Y una interpretación en bloque de constitucionalidad de ese dispositivo legal con el primer párrafo del artículo $201^{\circ}$ de la Constitución da como resultado que cuando la Carta Política dice que el TC es el órgano de control de la Constitución, lo es con carácter de «Supremo Intérprete» de aquella. No es el único, sin duda $^{26}$, dado que los ciudadanos y los poderes públicos (distintos al TC) estamos en aptitud de interpretar la Constitución. La relación con el TC es solo de predominio de aquel sobre la interpretación constitucional que todos podemos hacer, $\mathrm{y}$ ese predominio no lo practica solamente cuando ejerce control concentrado, sino también cuando aplica el control difuso.

\section{ALGUNAS REFLEXIONES A MODO DE CONCLUSIÓN}

Lo tratado en este breve trabajo da pie para una investigación mucho más amplia y de mayor rigor en la profundización de los tópicos aquí tratados. Como lo dije al inicio, este trabajo tiene fines descriptivos generales sobre cómo se encuentra implementado el sistema de control constitucional en el Perú.

En mi concepto, aún quedan algunas cuestiones sueltas por tratar: ¿Se justifica la variedad de procesos constitucionales de la libertad

26 Landa (2011, p. 618) señala que en una concepción "política" del "estatus" del TC, "se trata de una concepción que nace a partir de su reconocimiento -en última instancia- como vocero del poder constituyente, en la medida que es el supremo intérprete de la Constitución, aunque no el único». 
o deberíamos tender a uno solo?; ¿cómo diseñar un proceso cuyo trámite cumpla el estándar internacional del derecho a un recurso sencillo, rápido y eficaz que demanda la Corte Interamericana de Derechos Humanos, más aún si el Informe Defensorial N. 172 de la Defensoría del Pueblo demuestra que el proceso de amparo en la Corte Superior de Lima tiene un tiempo de duración de tres años, aproximadamente?

Estas preguntas constituyen, sin duda, materia para una segunda parte de este trabajo, puesto que si se toma como referencia el paradigma del Estado constitucional en serio, considero, radicalmente, que habría que repensar los instrumentos procesales de defensa de los derechos fundamentales. $Y$ es que se requiere de un solo proceso cuya estructura esté acorde con el estándar del derecho a un recurso rápido, sencillo y eficaz.

Mientras tanto, paralela a la reflexión anterior, el modelo difuso constituye una puerta abierta para impulsar y presionar por una judicatura ordinaria más activa en la tutela de los derechos fundamentales. Este tipo de control es, pues, un auténtico sistema difuminado en toda la judicatura y no es espacio monopolizado por la justicia constitucional. Es más, la peculiaridad de que el proceso de amparo peruano es residual, inspirado en el modelo argentino, tiene la relevancia de que es necesaria una toma de conciencia para los litigantes sobre el nuevo rol de esa justicia constitucional difuminada.

Por otro lado, considero que se requiere repensar el diseño de lazos comunicantes más directos entre la justicia constitucional difuminada y la de los procesos constitucionales de la libertad, incluyendo el proceso de acción popular, de tal manera que se articule un control constitucional difuso más coherente y consistente en cuya cúspide el Tribunal Constitucional ejerza, plena y absolutamente, el rol de supremo contralor de la Constitución.

Como se aprecia, la necesidad de toma de conciencia de los operadores jurídicos, por un lado, y la necesidad de ajustes normativos al sistema, por otro, me permiten afirmar que esta dualidad del control constitucional que presenta el sistema jurídico peruano constituye todo un modelo aún por armar. Y, en esa línea, debe apuntar la doctrina y la jurisprudencia constitucional en los próximos tiempos.

\section{REFERENCIAS}

Aragón, M. (2002). Constitución, democracia y control.México:UniversidadNacionalAutónoma de México, Instituto de Investigaciones Jurídicas.

Arenas y Loayza, C. (febrero de 1925). Discurso de Orden. Estudio sobre el desenvolvimiento de las instituciones judiciales en el Perú y la jurisprudencia de la Corte Suprema. La Revista del Foro (2), año XII, tomo XII. Lima: Colegio de Abogados de Lima.

Berizonce, R. (2010). Medidas cautelares, anticipatorias y de urgencia en el proceso de amparo. Revista Anales de la Facultad de Ciencias Jurídicas y Sociales, año 7 (40). Pág. 417 - 432. Buenos Aires: Universidad Nacional de La Plata. Recuperado de: http:// sedici.unlp.edu.ar/bitstream/handle/10915/20961/ Documento_completo.pdf?sequence $=1$

Bernales, E. (1998). Los derechos humanos y su protección jurídica en la experiencia política y social de América Latina. Pensamiento Constitucional (revista de la Maestría en Derecho con Mención en Derecho Constitucional de la Pontificia Universidad Católica del Perú -PUCP año V (5). Pág. 135 - 161. Lima: Fondo Editorial de la PUCP. Recuperado de: file://C:/Users/investigacion/ Downloads/3245-12237-1-PB\%20(1).pdf

Bianchi, A. (1992). "Control de constitucionalidad. El proceso y la jurisdicción constitucionales". Buenos Aires: Editorial Ábaco Rodolfo Depalma.

Blume, E. (1996). El Tribunal Constitucional peruano como supremo intérprete de la Constitución. Pensamiento Constitucional (revista de la Maestría en Derecho con Mención en Derecho Constitucional), año III (3). Pág. 125 - 205. Lima: Fondo Editorial de la Pontificia Universidad Católica del Perú. Recuperado de: file://C:/Users/investigacion/ Downloads/Dialnet-ElTribunalConstitucionalPeru anoComoSupremoInterpre-5085306\%20(1).pdf

Blume, E. (2014). Balance del fenecido Tribunal de Garantías Constitucionales (con énfasis en el control concentrado de constitucionalidad. En: Treinta años de jurisdicción constitucional en el Perú (tomo I). Lima: Tribunal Constitucional del Perú. Recuperado de: https://www.tc.gob.pe/ tc/private/adjuntos/cec/publicaciones/publicacion/ libro_30_anos_tomo1.pdf 
Burgoa, I. (1979). "El juicio de amparo” (14. ${ }^{\mathrm{a}}$ edición). México: Editorial Porrúa.

Canosa, R. (2013). La interpretación constitucional como modalidad del control del poder. En P. Häberle y D. García Belaunde, El control del poder (volumen I, 2. ${ }^{a}$ edición). Lima: Grijley, UNAM, Instituto Iberoamericano de Derecho Constitucional.

Eguiguren, F. y García, D. (2008). " $L a$ evolución político-constitucional en el Perú: 1976-2005". Estudios Constitucionales, año 6 (2). Pág. 371-398. Centro de Estudios Constitucionales de Chile, Universidad de Talca. Recuperado de: http://www.scielo.cl/pdf/ estconst/v6n2/art12.pdf

Fernández, F. (1996). El control de la constitucionalidad en Iberoamérica: sus rasgos generales y su génesis en el pasado siglo. Pensamiento Constitucional (revista de la Maestría en Derecho con Mención en Derecho Constitucional de la Pontificia Universidad Católica del Perú [PUCP]), año III (3). Pág. 231-264. Lima: Fondo Editorial de la PUCP. Recuperado de: http://www.revistas.pucp.edu. pe/index.php/pensamientoconstitucional/article/ viewFile/3347/3196

Fioravanti, M. (2009). Los derechos fundamentales. Apuntes de historia de las Constituciones (6. ${ }^{\text {a }}$ edición). Madrid: Editorial Trotta.

Fix-Zamudio, H. (1968). Veinticinco años de evolución de la Justicia Constitucional (1940-1965). México: Universidad Nacional Autónoma de México.

Fix-Zamudio, H. (1991). La justicia constitucional en América Latina. Lecturas Constitucionales Andinas (1). Lima: Comisión Andina de Juristas. Recuperado de: https://archivos.juridicas.unam.mx/www/bjv/ libros/2/703/3.pdf

Fix-Zamudio, H. (diciembre de 1988). El Juicio de Amparo y el Derecho Constitucional Comparado. Ius et Praxis (12) (revista de la Facultad de Derecho de la Universidad de Lima). Lima.

García, D. (1998). Lajurisdicción constitucional y el modelo dual o paralelo. Revista del Instituto de Ciencias Políticas y Derecho Constitucional: la justicia constitucional a finales del siglo $X X$, año VII (6). Huancayo: Palestra Editores.

García, D. (2004). Memorias de un juez (2. ${ }^{a}$ edición). Lima: Editorial San Marcos.

García, D. (2006a). La Constitución y su dinámica. Lima: Palestra Editores.

García, D. (2006b). Las Constituciones del Perú (tomos I y II). Lima: Fondo Editorial de la Universidad de San Martín de Porres.

García, D. (julio-diciembre 2008). La garantía jurisdiccional de la Constitución (la justicia constitucional). Hans Kelsen. Nota preliminar. Revista Iberoamericana de Derecho Procesal Constitucional (10). México.

García, M. (septiembre-diciembre de 1973). Algunos hechos y reflexiones sobre la historia de la Corte Suprema de Justicia de la República. Revista de Derecho y Ciencias Políticas, 37 (3). Lima: Universidad Nacional Mayor de San Marcos.

Guastini, R. (2016). Lecciones de Derecho Constitucional. Lima: Ediciones Legales.

Hamilton, A., Madison, J. y Jay, J. (2014). El federalista (segunda edición en español, quinta reimpresión). México: Fondo de Cultura Económica.

Landa, C. (2011). Autonomía procesal del Tribunal Constitucional: la experiencia del Perú. Proceso y Constitución. Actas del II Seminario Internacional de Derecho Procesal Proceso y Constitución llevado a cabo en el Campus de la PUCP entre el 10 y el 13 de mayo de 2011. Lima: Ara Editores - PUCP.

Lombardi, G. (2009). Estudio preliminar. En C. Schmitt, y H. Kelsen, La polémica Schmitt/ Kelsen sobre la justicia constitucional: el defensor de la Constitución versus ¿Quién debe ser el defensor de la Constitución? Madrid: Tecnos.

López, L. (2015). El precedente vinculante «Elgo Ríos» y el nuevo enfoque del rol de la Judicatura Ordinaria: de la «residualidad» a la «justicia constitucional difuminada». Diálogo con la Jurisprudencia (203), año 21, pp. 3140. Lima: Gaceta Jurídica. Recuperado de: http://www.academia.edu/25724673/Precedente_ vinculante_Elgo_R\%C3\%ADos_residualidad_y_ justicia_constitucional_difuminada 
López, L. (2016). Los «Poderes Judiciales», proceso y política judicial: una mirada desde el Estado Constitucional. Revista de la Maestría en Derecho Procesal 6 (2). Pág. 146-178. Lima: Pontificia Universidad Católica del Perú. Recuperado el 2 de agosto de 2017 de: http:// revistas.pucp.edu.pe/index.php/derechoprocesal/ article/view/16421

López, L. (2017). Para evitar el (des)amparo. Cinco pautas para comprender el modelo de la residualidad de los procesos constitucionales. $A A V V$. Por qué fracasan los amparos. El uso adecuado de las vías previas y específicas relacionadas con el amparo. Lima: Gaceta Jurídica. Recuperado de: http://www. academia.edu/33573480/PARA EVITAR EL

DESAMPARO. Cinco pautas para comprender el_modelo_de $\bar{l}$ a_residualidad_de $\overline{\text { los }}$ procesos constitucionales

Morales, J. (2000). Del Tribunal de Garantías Constitucionales al Tribunal Constitucional peruano. Análisis jurídicopolítico comparativo. Derecho PUCP (53). Pág. 65-88. Lima: Fondo Editorial de la Pontificia Universidad Católica del Perú. Recuperado de: http://revistas.pucp.edu.pe/ index.php/derechopucp/article/view/6555/6640

Moreso, J. (2014). La indeterminación del Derecho y la interpretación de la Constitución (2. ${ }^{a}$ edición). Lima: Palestra Editores.

Paniagua, V. (2004). El Anteproyecto de Constitución Política elaborado por la Comisión presidida por Manuel Vicente Villarán. AAVV, Homenaje a Jorge Avendaño Valdez (tomo I). Lima: Fondo Editorial de la Pontificia Universidad Católica del Perú.

Pérez, P. (2006). La cuestión de inconstitucionalidad en el Derecho Español. En J. P. Palomino Manchego (coord.), El Derecho Procesal Constitucional Peruano. Estudios en homenaje a Domingo García Belaunde (tomo II). Lima: Editora Jurídica Grijley.
Rodríguez, R. (agosto-diciembre de 2005). Amparo y residualidad. Las interpretaciones (subjetiva y objetiva) del artículo $5^{\circ} .2$ del Código Procesal Constitucional. Justicia Constitucional (revista de jurisprudencia y doctrina), año I (2). Pág. 97-136. Lima: Palestra Editores. Recuperado de: https://es.slideshare. net/AndrMoralesCarrilloI/2-rodriguez-amparo-yresidualidad

Rojas, J. (2004). Un nuevo molde para el amparo. Revista Latinoamericana de Derecho; Año I (1). Pág. 425 - 448. México: Universidad Nacional Autónoma de México, Instituto de Investigaciones Jurídicas, Rubinzal Culzoni Editores.

Sagüés, N. (2009). El amparo argentino y su reforma. En S. Abad Yupanqui y P. Pérez Tremps (coords.), La reforma del proceso de amparo: la experiencia comparada. Lima: Palestra Editores.

Sar, O. (2014). La jurisdicción constitucional en el Perú. En Treinta años de jurisdicción constitucional en el Perú (tomo II). Lima: Tribunal Constitucional del Perú.

Zagrebelsky, G. (2009). El derecho dúctil: ley, derechos, justicia (9. ${ }^{\text {a }}$ edición). Madrid: Editorial Trotta.

\section{BIBLIOGRAFÍA}

Rubio Correa, M. (1999). Estudio de la Constitución Política de 1993 (tomo IV). Lima: Fondo Editorial de la Pontificia Universidad Católica del Perú. 